\title{
Dos ejemplos de la política informativa de El Mundo en el proceso de pacificación del País Vasco
}

\author{
Dr. José María Caminos Marcet \\ Profesor Titular de Estructura de la Información Periodística. Universidad del País Vasco \\ Dra. Flora Marín Murillo \\ Profesora Titular de Teoría de la Imagen. Universidad del País Vasco
}

\section{RESUMEN}

El presente artículo es una pequeña muestra, aunque significativa, de un estudio mucho más profundo sobre la política informativa de los medios de comunicación a lo largo del proceso de pacificación puesto en marcha tras la tregua unilateral decretada por ETA el 17 de setiembre de 1998.

La elección del «proceso de pacificación vasco» para hablar de la posición que adopta la prensa en algunas situaciones conflictivas en las que confluyen importantes divergencias no es casual, ni tampoco inocente. Es una elección totalmente intencional, tanto como la propia actividad periodística respecto al caso que se analiza.

\section{ABSTRACT}

The present article is a small sample, although significant, of a deeper study about the informative politics of media along the process of pacification that started after the unilateral truce decreed by ETA in September, 1998. This study outlines how the election of the "Basque process of pacification" to talk about the position of press in some conflicting situations is not casual, neither innocent. It is a completely intentional election, as much as the own journalistic activity regarding the case that is analysed.

Palabras claves: Proceso de pacificación vasco/Nacionalismo/Medios de comunicación/Tratamiento informativo/Informaciones conflictivas.

Key Words: Basque process of pacification/Nationalism/Media/Informative treatment/Conflicting informations.

\section{Introducción}

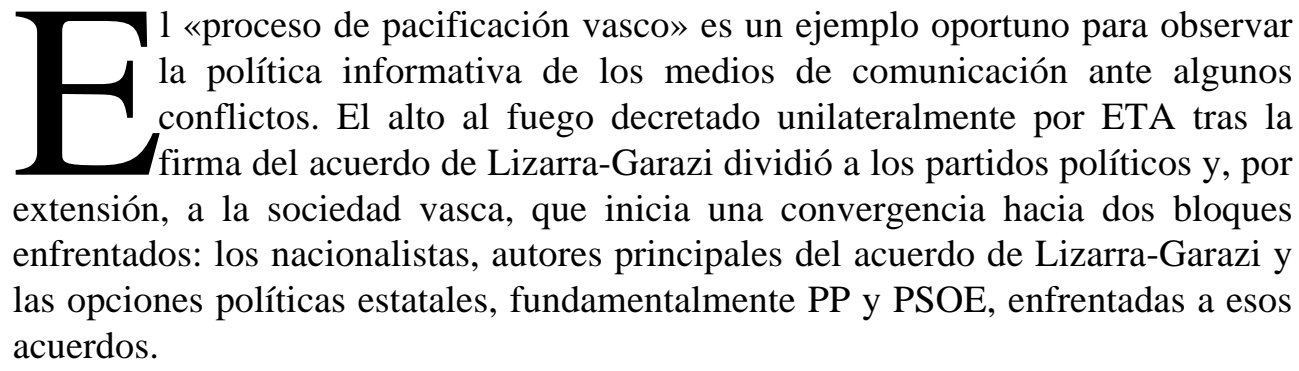


Una división que se ha ido acrecentando a lo largo de los últimos meses y que ha tenido como puntos álgidos la formación del primer Gobierno Vasco nacionalista desde la instauración de la democracia tras el acuerdo de gobierno alcanzado por el Partido Nacionalista Vasco y Eusko Alkartasuna y el apoyo exterior de Euskal Herritarrok.

La información sobre el proceso de pacificación en el País Vasco se convierte así en un hecho conflictivo, con posiciones abiertamente enfrentadas entre diversos sectores de la sociedad vasca, por lo que los medios de comunicación, durante los meses que este tema está formando parte de su agenda informativa, van dejando inevitablemente unas huellas que indican claramente su posición, su estrategia informativa.

Para realizar estudios cualitativos sobre el tratamiento informativo de los medios de comunicación siempre es oportuno acudir a momentos en los que aparecen informaciones conflictivas, porque es en esos casos cuando los medios se posicionan con mayor facilidad en una u otra dirección.

Un día cualquiera, en el que apenas existen informaciones conflictivas, los medios de comunicación pueden mantener una política informativa marcada por la uniformidad. En esos casos es difícil que aparezcan discrepancias de fondo entre los medios de comunicación.

El «proceso de pacificación vasco» es oportuno porque reúne los ingredientes necesarios para que los medios de comunicación tomen postura, se impliquen directamente en el tema, como de hecho así sucede.

A la hora de abordar este trabajo, hemos desechado los análisis cuantitativos, porque no se ajustan al objetivo del estudio que se pretendía. Una observación fundamentalmente cuantitativa nos hubiera aportado pistas sobre la importancia que el proceso de pacificación en el País Vasco está teniendo en los medios de comunicación: Si forma parte de su agenda temática, la importancia que le conceden, el espacio que dedican, las veces que aparece en portada, si se editorializa con los temas, etc. Un enfoque de interés, pero alejado de las pretensiones de un estudio que ha buscado centrarse fundamentalmente en los contenidos de los textos periodísticos aparecidos en los medios de comunicación.

Hemos preferido efectuar un análisis de los contenidos de los textos periodísticos para encontrar con mayor nitidez las claves de la política informativa que los medios de comunicación están manteniendo a lo largo del proceso de pacificación vasco.

Para la realización del estudio hemos analizado las informaciones y los editoriales publicados por los medios de comunicación sobre estos apartados. Hemos dejado de lado las columnas de opinión, por considerar que no reflejan el punto de vista del medio y sí de los autores de las mismas, por lo que no tienen por qué ser coincidentes con la del medio de comunicación que las publican. 
El artículo que aquí presentamos recoge la política informativa del diario $E l$ Mundo en dos acontecimientos relevantes sucedidos durante la tregua de ETA: La decisión del Parlamento Vasco de prestar su sede a la Asamblea Kurda en el exilio y las posibilidades de mediación de la Iglesia vasca en el conflicto y más concretamente la de monseñor Setién.

\section{I.- EI drama kurdo: Una "realpolitik" de doble rasero}

1. Un problema complejo

El 9 de febrero de 1999 la Mesa del Parlamento Vasco -con los votos a favor de PNV, EA y EH y la oposición de PP y PSE-EE- decidió ceder la Cámara de Gasteiz para que la Asamblea Kurda en el Exilio pudiera reunirse el mes de julio en la sede del Parlamento Vasco.

Esta decisión solidaria con los representantes del pueblo kurdo, en el contexto de la solidaridad internacional, no era un acto aislado del Parlamento. En los últimos años, los representantes kurdos, ante la imposibilidad de reunirse en su propio país, se han venido juntando en algunas de las capitales más importantes de Europa. Así, la Asamblea kurda ha tenido como sede La Haya, Oslo, Copenhage, Moscú, Roma y Bruselas.

La autorización del Parlamento Vasco para utilizar su sede de Gasteiz tampoco era el primer acto de solidaridad que algunos partidos políticos vascos mantenían con representantes del pueblo kurdo, sometido a una feroz persecución por las autoridades turcas.

El 29 de marzo de 1995, el PP, PSE-EE y UA, junto a los partidos nacionalistas, recibieron en el Parlamento Vasco a una representación del Parlamento kurdo en el exilio. Zubeyir Aydar, representante del parlamento kurdo, y Delil B. Yilmaz, del Frente de Liberación Nacional del Kurdistán, se reunieron con la Comisión de Exteriores del Parlamento de Gasteiz.

En marzo de 1996 representantes del PNV, PSE-EE, HB, PP, IU y UA se reunieron en Bruselas con miembros de la Asamblea kurda y compartieron mantel en una cena que tuvo lugar en esa capital europea. La cena fue organizada por los representantes de la Asamblea Kurda en el Exilio, que pretendían así establecer relaciones con los partidos vascos con representación parlamentaria en la Cámara de Gasteiz.

Además, PP, PSE-EE y UA, junto con los nacionalistas, han aprobado en los últimos años en el Parlamento Vasco una proposición no de Ley y dos declaraciones institucionales en las que se solidarizaban con el Kurdistán y condenaban la agresión de Turquía hacia el pueblo kurdo.

Sin embargo, las relaciones entre los representantes parlamentarios vascos y los del pueblo kurdo no han dejado de ser claramente contradictorias, debido fundamentalmente a los altos intereses económicos de empresarios vascos y españoles con Turquía. 
Así, mientras se producían estas declaraciones de solidaridad de todos los partidos vascos sin exclusiones con los representantes del pueblo kurdo, el Gobierno Vasco aprobaba, en 1992, una importante ayuda económica, superior a los 700 millones de pesetas, a la empresa Expal, perteneciente al grupo Unión Española de Explosivos.

Explosivos Alaveses (Expal) produce desde 1998 un pedido de cientos de bombas aéreas para el Gobierno de Turquía, bombas que comenzaron a entregarse a finales de 1998 y que, presumiblemente, se podrían estar utilizando en la lucha contra el pueblo kurdo.

En 1997 el Gobierno Vasco subvencionó una misión comercial a Turquía, para ayudar a los empresarios vascos a introducirse en el mercado turco. En 1998 las exportaciones de la industria vasca a Turquía ascendieron a 11.500 millones de pesetas $^{1}$.

Así pues, la solidaridad de todos los partidos políticos con representación parlamentaria en Gasteiz con el pueblo del Kurdistán no es nada nueva. En los últimos años ha habido varias muestras de las buenas relaciones existentes entre los representantes kurdos y el Parlamento Vasco. Una solidaridad que, sin embargo, se ha ido manteniendo al tiempo que se fortalecía una política comercial expansiva con Turquía, fundamentalmente en el campo de la venta de armamento.

\section{La decisión parlamentaria en $\mathrm{El}$ Mundo}

Los medios de comunicación publican el día 10 de febrero la noticia sobre la decisión adoptada por la Mesa del Parlamento Vasco en la que decide prestar su sede de Gasteiz a la Asamblea Kurda en el Exilio. Ese día, el diario El Mundo titula en portada: El Parlamento Vasco cede su sede a la Asamblea kurda en el exilio como muestra de su soberanía.

Desde el primer instante el diario El Mundo manifiesta su disconformidad con el acuerdo aprobado por la Mesa del Parlamento y en su titular de portada, al afirmar que la decisión es una forma de expresar la soberanía, presenta la resolución como un intento más de los partidos firmantes del Acuerdo de Estella de mostrar hacia el exterior la soberanía del pueblo vasco.

En las páginas interiores, abriendo la sección de Euskadi, El Mundo titula: El Parlamento permite a la Asamblea kurda reunirse en Vitoria pese a la dura oposición de PP y PSE-EE.

(1) Los datos sobre las inversiones comerciales en Turquía y las subvenciones del Gobierno Vasco aparecen publicados en El Mundo, miércoles 16 de febrero de 1999. 
Se trata de un titular altamente significativo, ya que al afirmar que el Parlamento Vasco ha aprobado la resolución pese a la dura oposición de PP y PSE-EE. El Mundo está dejando claro que la dura oposición del Partido Socialista y el Partido Popular era un argumento suficiente para que el acuerdo no fuera aprobado por la Mesa del Parlamento Vasco. El Mundo se alinea a favor de los preceptos defendidos por el PP y PSE-EE y sitúa el tema en términos de confrontación entre los partidos nacionalistas y los que no lo son. Hubiera sido diferente que El Mundo hubiera destacado en su titular que El Parlamento permite a la Asamblea kurda reunirse en Vitoria con la dura oposición de PP y PSE-EE. 


\section{El Parlamento permite a la Asamblea kurda reunirse en Vitoria pese a la dura oposición de PP y PSEEE}

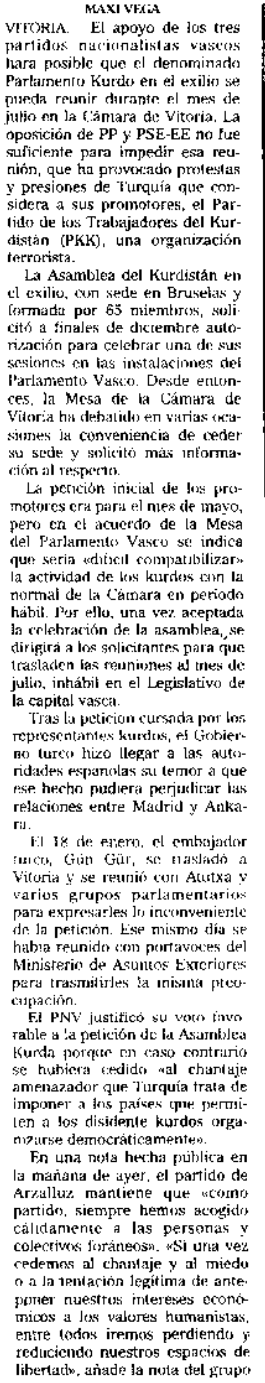

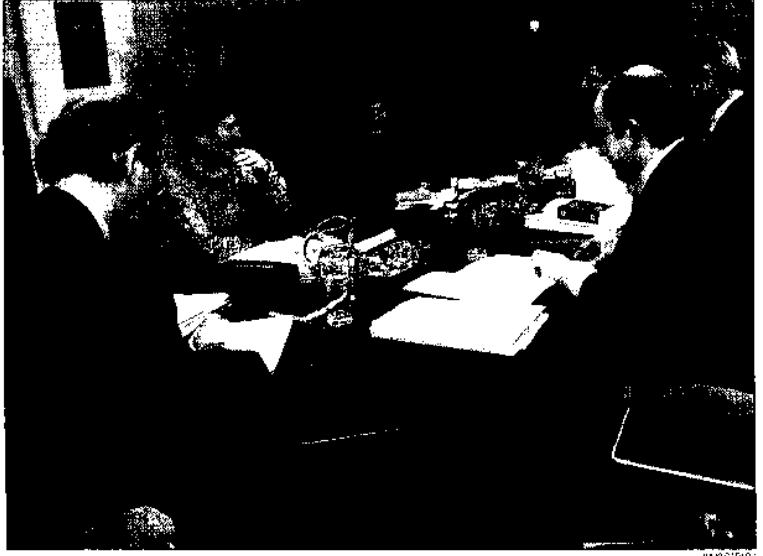

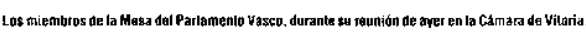

parlamentario naciunadisti.

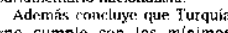

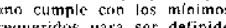
tomou un sislema demencráticon de liberiadis:

Fid yrosidente del Parlamentris

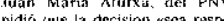

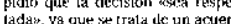

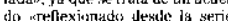
dast y la screntadudu

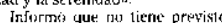
mantemer ningýn contatito conn el Ministelio de Asunces Fixlenore

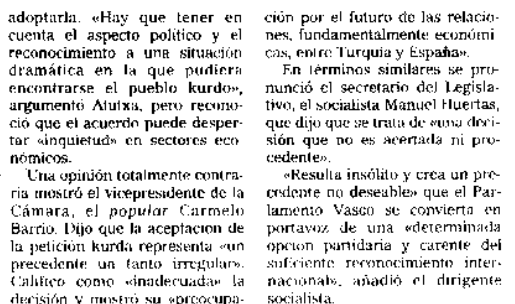
a'rohibiremos la entrada de los kutdos ilegalewo

MADSRII!- El menistro de Asugtos findericotes, Ahei Macutes, advitio ayer yue bich (1)

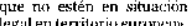
Marules senialo que tras ian decision de! Parlamento

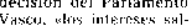

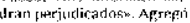
itue log ptoxtos no so cir.

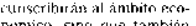

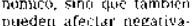

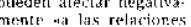
contre lats dos paises.

En porregidos lentrinuse expreso la ministle de lus

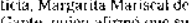

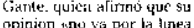

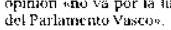
Fuerres de La Morded

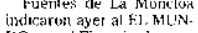
bo que el Ejecutjol klit reaante el Goteremo gurso pata pedirle que actúc con moderación en oste contencioso. los mediadores esparioles hàly insistinto mo que nor se.

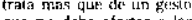
que no debe afedtar a (iquentes divilom. aroetes diplomatce.

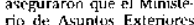

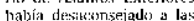
gistoridiade wats the:an a kos kurdes purqui

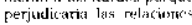
entre Espariaty l vingulita

\section{Turquía cree que la decisión «ayuda a dar coraje al terrorismo»}

MADRIT - I It Finhmijadis de lurquia en Lispasia ronsiderst que la dectisiton pernsitir una relunión en pernatir una rellnion en laurunu kurdo en el exi-

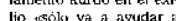
dat woraje at mertiristhy de] [rok y corrorismo cen atereraly, segun ha indicado ay portiny $\mathrm{Hilm}$ Dedegelu aEs una decision que ha lomatos ef Farlamento vascrms, tha indicada e] poilaver? fuien ha suthrayado que la Camara de viloria puede torratr rastiss der Giones, peren edde nuestras

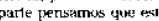

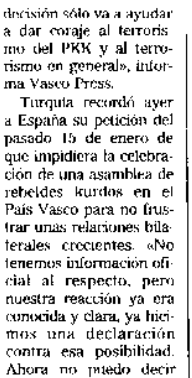

atid mis pues hemos cilp revisar los ntheres
hechus de ia situationm, dijo it FFe Haldur Gtenan, diretety de Infor mación del Mirsis
turon th Exteriom:

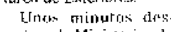
puses, el Mirisistercio de bixceriores extritin ura declaracion onficial en lat quir dijo :ener unforma cime's subre un phisible intento de. lia axamblea de los kurdos rehreld:s de reunirse err ia iadla del Parkactento murcipeo. Arteara dije cosperar que ef Eureparlumentor rino se comvertini ent jisteru

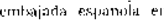
Allkarra, huan aristegui,

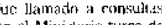
Exleriotes un Inirimi

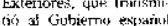

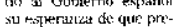

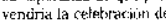

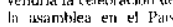
vilects

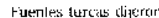
experar que el puetilo.

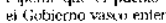

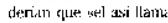
do) pritlamenty kaurdo en

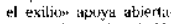
nicalier al parteto webelde

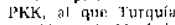
concidera culpable de la

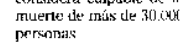


En el resto de las informaciones publicadas durante esta primera jornada $E l$ Mundo se dedica a destacar los posibles aspectos negativos que la decisión puede acarrear para la economía y política vascas. Ni una sola versión que contradiga su punto de vista opuesto al acuerdo.

Así, la totalidad de las informaciones publicadas en sus páginas interiores están orientadas a poner sobre la mesa el revés de la decisión:

- Explica la política oficial del Gobierno de Madrid, enfrentada a la decisión tomada por la Mesa del Parlamento Vasco.

- Destaca la posición oficial del Gobierno turco que califica de terrorista la lucha de los kurdos.

- Expone el punto de vista crítico de la Confederación de Empresarios Vascos, preocupada por las consecuencias económicas de la medida.

- Destaca el volumen de las exportaciones vascas a Turquía para fortalecer los argumentos favorables a su punto de vista.

- Mediante una selección ventajosa elige el punto de vista de dos catedráticos contrarios a la decisión. Esta elección contribuye a dar la sensación de imparcialidad, pero selecciona a dos personas que fortalecen con sus puntos de vista los argumentos del periódico. 


\section{Confebask alerta del «grave perjuicio» para la economía del País Vaseo}

Explica que Fưquia orupa el puesto 21 en lá lista de países con los que Euskad mantiene relaciones comerciales

BIl_BAO. La Confedoracion Empresarial Vasca, Coptetbasts.

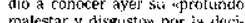
sión de autoojizar que el Parla mentis kurde en el exilis celehre

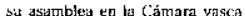

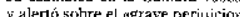
que osie hecho supondrai parai exononía vasca

La pattonal vasca se Jelirió a as relaciones exnncimicas que accualmente egtan establecidas entre Turyujin y t.uskarli para poner de manilicsto yle und postbic ruptura crire elmptesias do

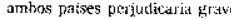
mesule a la econornia vasca.

Fin rotactoto, Cinfébask subriayó que existe un grat aumejer de empresas vascas que "irks. muchos antios dt exfuerzosia se. Lan ititrmducido en el pedifici

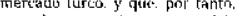
pura la Penter bin shmprtation Asi, inclici que actualmente

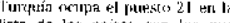
Eulke comerciales:

Aderrás, la pattontal cisci Anto que $h$ previsiones aping

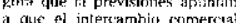

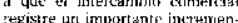

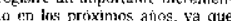

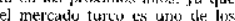
mejgentes y con emays proch-

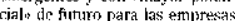

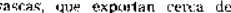

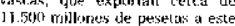
pais. Adernis de aphntis malks

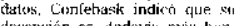

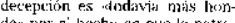
dan por ei hechos ac que las pritronal yo habis ofmunictuto pervitinence al Parlomenos su wpinix cobse pith cuestrisin.

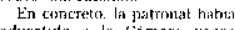

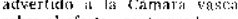
snbe el efereso scontraproulucertse risponsalpilidats pos las conse?

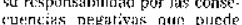
tener paru its tompresess vilitens. Par úlimo, Ja paltonal vasce ariadio que resta delcrmimacich se

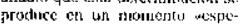

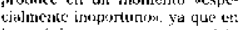

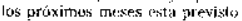

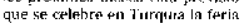
Expotectrian

('irculo de limpresarios

lucede en Circulo de tempresaries Vascos también se prudujeron criticas en el misino sentito contra la decision de acoger a lox

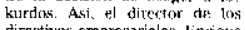
Portocarrero, andvirio de qute

veces upon haceg gesins que son Un pous a la yaleriabr, se pueden producir

En dexlaracunes mo En deriationtes enalizadas a agoncia a Futopa Press. Por de

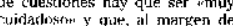
que ke rexil el respeto a los demo ches lumenos de a a las dere

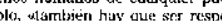
uosio con as momas mternas oxtermas

El directore dal circuls de thiptesatiós apuntitló su

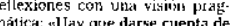
Gur: en el clebate politicu, :ambintr ke pueden mas:manar graves per juicios saciales y econtómicos.

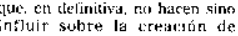
moplestom.

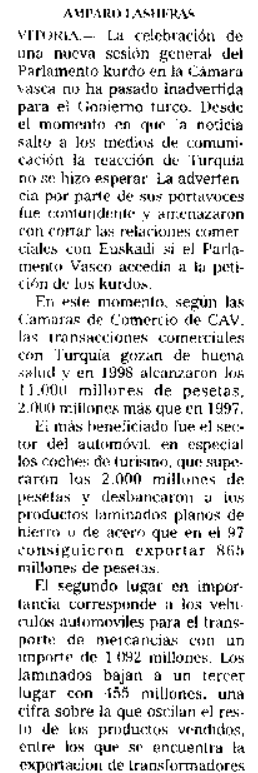

III) A an la

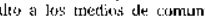
enperar La adperten (1)

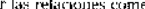
Euskald in el Fart

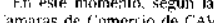

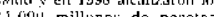

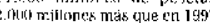
Ea mas pegaticiado lue di ke

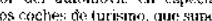
moros less 2.000 millones it

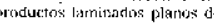
nzillyones de pesel jus. F. segundo lugat on impor prite: de metcariciá cost anmonados bajart at un tercer

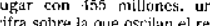

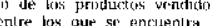

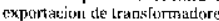

\section{Las exportaciones vasuas a Turquía superan los}

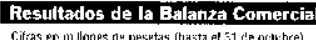

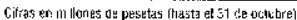

1998

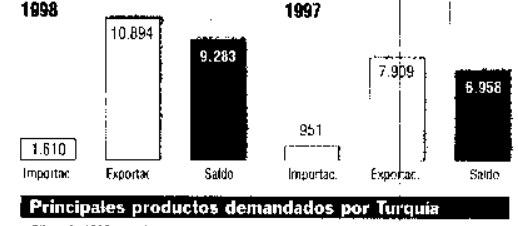

1997

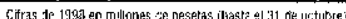

-

- Coches to lurkine y otros rehiculos

- Yehicales para trat trasponte da mencancias

- Productos lamiliados planos de hiorre o searo

- Transiornadones olectulcas y cenvertldores

- Partes y aceserras

- Refrigeradores y congeladores

- Utiles intercantablas pam herramlentas te mano

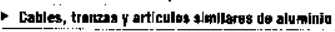

- Kelumátleos nagros do cascho

- Mticulos do grileria y árganus pasa tuberias

- Rèrölyares y pistolas

- Bomber, granadas do mani y municilion I0T:51

-

(a)

Un aculerdo "peligroso", según dos catedrúticus

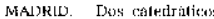
de Derecho Constilucimbal cali.

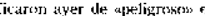
it'uerdo atdoplisto portel Farridmento vasco de permirir que el Parlathentes kurds en el exilit colebue una reunion ela las me. ralacingers de la Camara legis.

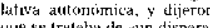
yue sie IrHabsh de wun disparts tew. ded Departimento de Denectu Canctituciunal de a L Lingersiduad (hompluteense de. Mandrut y

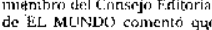
de EL MLLNDis comento quo

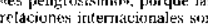
cacompetencia excllusiva de: Estadoy yel parlathentio are unic

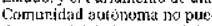
de lomar inicialivals ent Föluica

Par su parte. el caredration de Derentuo Cinssituciunal de la bniversidadcompriutence de Madrid Pedro de Vega djos que al cit Parlamento surlo se ricune en la chathara wasca

Yor whstance, arlasri) que acic)

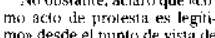
morm desde el funto de wicka de

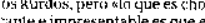
Pariamento del Pais Yasero ast-

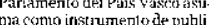
cidlad algo quevs contra la logicis parlamentarias. clectricos con 5566 millones; par.

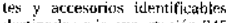

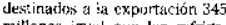
rene radores

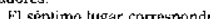
Lios titus intor comesponde a los umientas de mano para alcanzon los $32 \%$ millanes. Segujdos de los $3 \% 2$ milones do la induscris de cables, irenzas $x$ ortos articulus similates de lumini

Lus nermmaticon nuevos de caucho aparisen en tl nurenis ugar con 314 millones pot

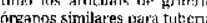
que no sobrepasabl los 28. mithros

Fin cusentrs a ta exporkacion de imamerlo, senglada jor el presidente del EBB de] PANG: sibjer Arzalus, como una de als industrixs vaschas gue má

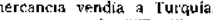

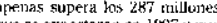

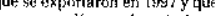
chropend

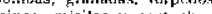
mimas, misiles y

t." 1998 el descenso mas espectarulur en el rarking de renducton exprortados por la dus que bajaron mas de aty millines las neumatios trucros de coucho son un descens d

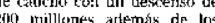
ariculck de griteria. las miguimas de lavar y bas clapas y ban
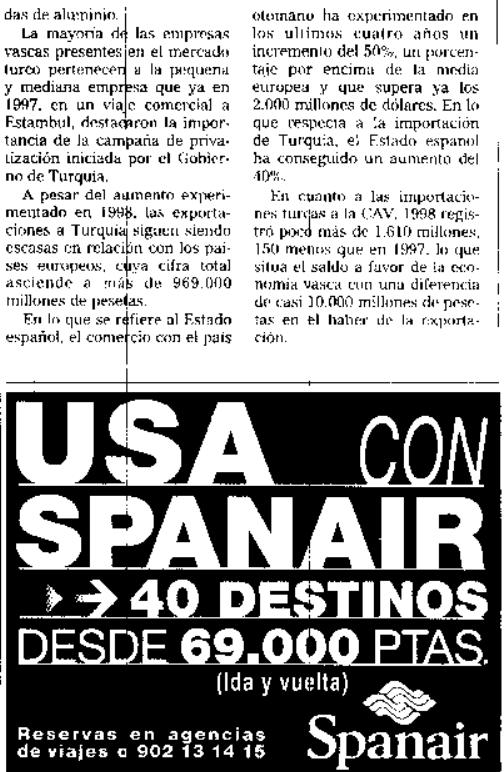
El Mundo deja clara también su postura contraria a la decisión adoptada por la Mesa del Parlamento en un pequeño editorial (glosa) en el que utiliza dos tipos de argumentos:

1. Un bloque de argumentos de carácter económico:

- La decisión no sólo puede crear una grave crisis diplomática entre España y Turquía sino que va a tener efectos en las relaciones comerciales.

- La propuesta va a irritar a los turcos sin ayudar a resolver la situación del pueblo kurdo.

2. Otro bloque de argumentos de carácter político:

- La comunidad vasca no tiene competencias en materia de política exterior.

- Los nacionalistas han querido propinar una bofetada al Gobierno de Aznar.

El día 11 El Mundo intenta ahondar en las posibles fisuras que una decisión de ese tipo pudiera provocar en el Partido Nacionalista Vasco y titula en su portada: Consternación entre empresarios próximos al PNV por los riesgos del hermanamiento con los kurdos.

El periódico, que recoge las críticas de Confebask (Confederación de Empresarios Vascos) a la medida aprobada por la Mesa del Parlamento Vasco, titula en sus páginas interiores: Empresarios nacionalistas comparten la preocupación por la invitación a los kurdos. 


\section{LA TRONERA \\ ANTONIO GALA \\ Esperanza en el Senado}

Quien piense que a ksperanza Aguirte ta han iman dado a inverthar al Senado, creo que piensa mal. aunque fuese la intención del jefe. Si algo qued por hacer en Espaja (sic). es el asuntazo de l Camara Alta, al qut? madie se ha atrevido a hinca el diente. De haherse hceho, quizá of ros gallos cart tatar hoy y no escuchariamos tanlo mugido. Aguirre ha sabido siompre lo que hace, se peluvocara o no. Su candidatura ro es thena solo por mujer. sirno por mujer hábil. con opinión vivida sobre nacionalismos, abierts $y$ de inmediatas reac ciones: una política, por lantu. Esperemos en Esperanza. No nos defraudaria si la dejasen, claro. Acebes, sin subir más, qué pena.

\section{El PP se equipoed y extiende. "sospechas» sobre Piqué}

\begin{tabular}{|c|c|c|}
\hline 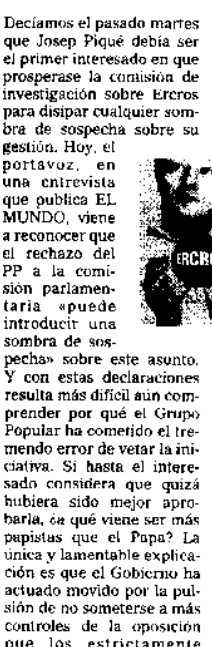 & 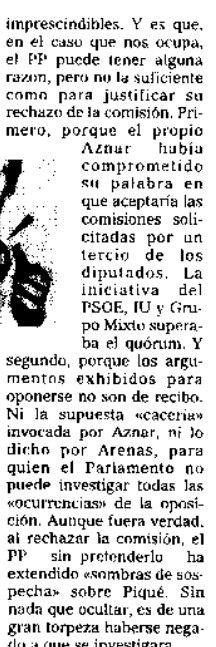 & 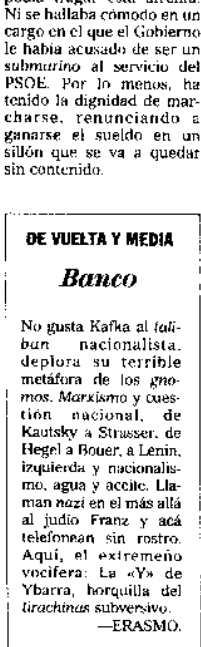 \\
\hline
\end{tabular}

\section{RICARDO Y MACHO}

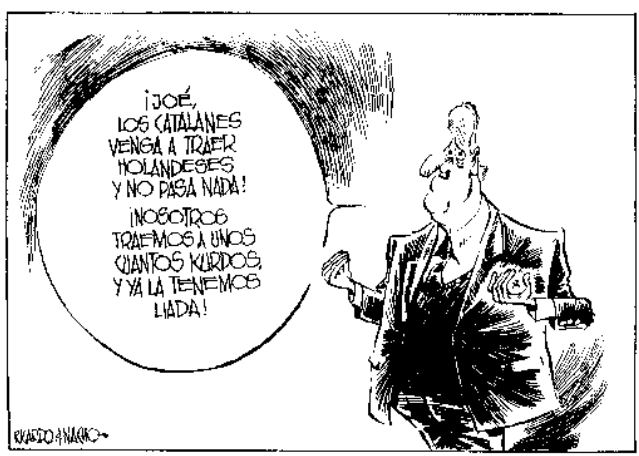

\section{El úlfimo gesto de Fermandez Ordoner}

Miguel Angel Fernendez Ordónez proschtó ayer yu Jimiston conth presidente del Sistema Flentricio, cargá en al qui: Lodávia le que E-n su carta de rcnuncie constinución de la comizion Nacional de la Energi duplsidad mon fel ofganismo que él ha presididto desUe hace cuatro antiss. Y no no dice gs yue mo está dispuester et asurnir un pape de suhwodinacion a la nuewa Comisión. prevista en 1 Ley de Hideccashuros Maro, cumo lo leaman lo antigos colnquialmente, $\pi$ Wis hallata coma afrenta. cargo th cl que el Gohierm le habia acusitud ate ser un psote for lo menos, ha atenjoo la dignidad de mar sanarse of sueldo en an silorn que so va a queds

\section{DE YUELTA Y MEDIA}

No gusta Kafhat al foutbum macinalistista metafira des los thoin acional, de Regrl a

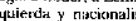
mo, agua y accile Lla al judio Frane $y$ ace fompan sin rostro Aqui, el axtremeño barra, mareutullas tel En su carta de mandato. LTeará un problema de hostrano, en realidad. no es que se tuya decidido cambiar la formula de juramento militar a la bandera, sino que la anterior haya pervirido hastia ihora. No sólo port la rétorticia Ilama. tivamente areaice do su Iextó, sino también porque exigia del militar la expresion de un juramento - no bak taba corl la promesa-- y. sobre todo, porque destacaba de manera unulateral y al merren de la oblización de Hefender el orden constilucicmat, la de

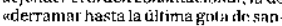
gren para presetvar la nunidad e integridad territarial de la Patrian. Una mención que en el mejor de los casos resultaba redundante --ya se hakla de exte deber en el articulado de la propi: Conristitución- $y$, on el peor, un anddido muy peligtosu, que podía servir de cuartides a al annos militares para actuar mas alia de los limites marcados por las leyes. Algu nada desdenable en un pais en el que las Fuerzas Armiadas se han corsiderado tanta veces en el deber dé inter ade tantas veres ellas de la sociedad civil invocen. do precisamente wla detensa de la unidad de la Patrian.

Eл da Fispana actual, integrada a todos lon miveles - tambien. y muy todos los riveles -tathbien. y muy organos de decisión suprinacionales que son absolutamente insumpatibles que son ebsolutamente inkmmpathlhs
con cualquier veleidad iniervenciocon cualquier veleidad intervencio-

\section{EL PNV Y LOS EMPRESARIOS}

La decisión de ios nacimnalistas de ceder la sede del Fartamento Visco a la Asarablea kurda en el exiito prownc ayer una dura reacrión. de Confebask le patronal vasca. José Guillermo Zuhia, su netretasyo, exprtesó stu remalestar y precorupactoon y aseguró que Is irichativa va a tener *efectos negatiyns sobre las exportaciones de la industria vasca a Turgusa, que ascendie por a 17 . 500 millunes en 1998 .

El analestaro de Confetragk resulta tadavía más comprensible si se tiene en ctuenta que el propio Gobjerno de Ajuria Enea subvencion ó una misioñ comercial a Turguia hace ano y medio. PNV y EA, que formaban parte de aqued Gabinete, sotarin anteayer a favor de la propuesta que puede cerras lás puertás det mercado turco a los puroducilos vascos y de todo el Estado. Conserimportante el daño conkr et que esta iniciativa puede causar, to que esta iniciativa puede causar, lo
más preocupante para el empresariamás preocupante phra el empresaria-
do vasco es, sin duda, la progresiva acelerada radicalización del $P N W$, $\mathrm{e}$
10. No hay yaespaciom el que puedan aseftarse as delifios de los Tejeras. Pero, con tado y con eso, siempre es mejor que las formas correspondan frelmente a lus contenidos.

La taheva fürmula propuesta por el Gobjerno, que ayet fue aprohada por a comision ad hot del congresio esuelve la cezestión del modo más sencitlo: exige de fos mijtares que then o prorthelan aguardar y hace cuardar la consritucióls como notma fundamental del Fistados. Lo cual implica defender ra santo en su forma actual como en cualquier otra que pudierd adoplat en el futuru si quien es el sLijeton de la soheratia es dectr. ef putalo espatiol-- tornara la libre decisión de reformasla.

El proyecto de Lay de Régimen de: Personal de las Fuerzas Auradas, yue pleno del congreso de los Dipurados para su aprobración inclupuados cambios que coniribuinan a incos aún mas que contribuiran a aderuar aun mas a luestras fuerzas Armedas áa rélidud de la España de hoy. Asj el ar. 70, apartado b), establece como criter io rector al que deberán ateners throros planes de estudio die la scalas de milifares de carreta, el de comentar los principios y valore consiales

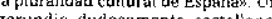
geto una excelente ido

partido mas votadón en la comuridad y su alianza estrategica con $\mathbf{E H}$ I a firma del acuerdo de F.sinella, la prisencia en la llamada Asamblea de pendentista de la diresción dol PNV pendentista de la direccion dol PNo provoca of rechazed un seclor mino. que gobierna Fuskadi, cada día más que gobierna Fuskati, cada dáa más purencul phadn por lit reperrusion que Tla indust rit vasca.

bil. PNy no sots cote af rekgn do perder all apogro de psta sestspr macion-

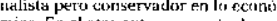
mito. En el arro extremck. parte de sus simpat lisantes podrian tambien uec:anlarse pur volar a la izquierda aberlat c. Torlulecide 4 rass le trogua de ETA jua formacion de Arzalluz esta jugando con fuego. Y su fripola impliación en la causa kurda no ha hecho mís que poner de telieve lass contradieciontes de un partidogutee, st se hábi caraclerizado hasla la fectha por una notable ambiguedad ideologica, a hora parece cada vez mas escorido. 
Al elaborar esta información, El Mundo vincula interesadamente a Confebask con empresarios próximos al PNV o empresarios nacionalistas.

Dentro de Confebask existen, qué duda cabe, empresarios vinculados o cercanos al PNV, pero Confebask nunca ha aparecido como una organización empresarial cercana a ese partido, ya que entre sus miembros existen, cómo no, empresarios cercanos al Partido Popular, Unidad Alavesa, Partido Socialista Vasco y a cualquier otra opción política.

El Mundo utiliza un recurso claramente desinformativo que busca crear contradicciones entre un sector del empresariado, posiblemente cercano al PNV, y ese partido político.

En un editorial publicado ese mismo día y titulado El PNV y los empresarios, el periódico critica una vez más la decisión tomada por el Parlamento Vasco y censura lo que llama la progresiva y acelerada radicalización del PNV.

Para argumentar lo que El Mundo denomina radicalización del Partido Nacionalista Vasco, el editorialista de ese periódico vincula la decisión de la Mesa del Parlamento Vasco con otros acuerdos políticos adoptados en los últimos meses por el PNV, EA, EH e IU. Acuerdos que, según ese periódico, son rechazados por sectores minoritarios pero de gran influencia dentro del PNV.

Así, El Mundo expone en su editorial que: La firma del acuerdo de Estella, la presencia en la llamada Asamblea de Municipios Vascos y el discurso independentista de la dirección del PNV provoca el rechazo de un sector minoritario pero muy influyente del partido que gobierna Euskadi, cada día más preocupado por la repercusión que puede tener esa actitud sobre la banca y la industria vasca.

Apoyándose en estos argumentos, El Mundo acusa al Partido Nacionalista Vasco de mantener una frívola implicación en la causa kurda.

El día 12 de febrero El Mundo recoge en su portada las presiones que se están llevando a cabo desde el Gobierno de Madrid para dejar sin validez el acuerdo del Parlamento Vasco. Así, titula en su portada: Aznar presiona a Ibarretxe para que se retire la invitación a la Asamblea kurda. Al mismo tiempo recuerda, también en portada, que Una empresa de Alava que fabrica bombas para Turquía recibió ayudas del Gobierno Vasco.

En la información que publica en las páginas interiores, El Mundo titula: Aznar pide a Ibarretxe sensatez para evitar que los kurdos se reúnan en el País Vasco.

La solicitud de Aznar de sensatez a Ibarretxe, en ese mismo preciso término, no aparece durante esa jornada en ningún otro medio de comunicación. Al afirmar en el titular que Aznar ha pedido a Ibarretxe sensatez, el periodista está utilizando una interpretación de la posible intencionalidad del orador. El periodista desconoce si Aznar ha solicitado exactamente sensatez a Ibarretxe. Ha podido solicitarle que reflexione, medite sobre la decisión, que cambie su punto de vista, etc.., pero intencionadamente $E l$ Mundo habla de sensatez. 
Con ello, utilizando intencionadamente un término que desconoce si ha utilizado Aznar, descalifica al contrario, al tiempo que califica de insensata su decisión.

En esa misma información explica los argumentos del Gobierno para oponerse al acuerdo:

- La decisión supone suplantar las competencias atribuidas en exclusiva al Ejecutivo central.

- No estamos hablando del pueblo kurdo ni de su situación, sino de la cesión de unas instalaciones en territorio español.

- El Gobierno ha puesto en marcha a tres ministerios -Exterior, Interior y Administraciones Públicas- para buscar la forma de impedir legalmente la reunión.

- La decisión afecta a empresas españolas y vascas con nombres y apellidos; a trabajadores vascos con nombres y apellidos y a circunstancias económicas sociales y políticas.

El día 14 de febrero, Pedro J. Ramírez, en la carta que publica todos los domingos en ese periódico, explica en una breve frase el punto de vista de su diario frente al tema kurdo: Una cosa es solidarizarse con el pueblo kurdo -y con el tártaro, y con el de Timor Oriental- y otra empezar a convertir Euskadi en la meca de los parias de la tierra.

Un argumento claramente demagógico y totalmente contrario a los preceptos que como veremos posteriormente afirma defender ese medio de comunicación.

Este mismo día, vuelve a destacar los intereses económicos de España con Turquía y las repercusiones que la medida adoptada por el Parlamento Vasco puede tener en las relaciones comerciales. En sus páginas interiores publica un artículo que titula: CASA se juega $\mathbf{2 0 . 0 0 0}$ millones de pesetas en Turquía con un subtítulo en el que se lee: Muchos jóvenes de Ankara compran en las tiendas de Mango y Zara, ajenos a la polémica.

\section{La detención de Abdula Ocalan}

El problema de la solidaridad internacional con el pueblo kurdo da un vuelco espectacular el día 16 de febrero de 1999 con la detención de Abdulá Ocalan, líder del Partido de los Trabajadores del Kurdistán, la principal organización kurda de Turquía que mantiene una lucha armada desde 1984 para conseguir un estado federal y que tiene como brazo político al Frente de Liberación Nacional del Kurdistán.

La detención de Ocalan se llevó a cabo en Kenia en una complicada operación en la que, al parecer, intervinieron miembros de la CIA, los servicios secretos israelíes y responsables turcos, que son los que mantienen en la actualidad detenido al líder kurdo. 
El día 17 los medios de comunicación publican la detención de Ocalan. El Mundo se ratifica en los argumentos que ha estado defendiendo los días anteriores, e incluso se muestra aún más contundente, a pesar de reconocer que el Gobierno turco, país en el que existe la pena de muerte, podría ejecutar al líder kurdo.

Así, El Mundo, en un editorial publicado en su página 9 titulado La peligrosa desesperación kurda, después de afirmar que probablemente el Gobierno turco no se atreva a ejecutar a Ocalan, argumenta lo siguiente:

La comunidad internacional nunca se ha tomado gran interés por este conflicto. La Realpolitik se ha impuesto, exacerbando la desesperación kurda. En este contexto, queda patente la frivolidad del Parlamento Vasco que, con su invitación unilateral al exilio kurdo, sólo puede verse enredado en una compleja madeja de tensiones internacionales y, tal vez, en una espiral de violencia.

Una vez más reivindica la insolidaridad, destaca la importancia de lo que denomina Realpolitik y no duda en calificar de frivolidad la actitud solidaria con los kurdos mantenida por el Parlamento Vasco. 


\section{LA TRONERA \\ ANTONIO GALA}

\section{Camuanal interminable}

Pese a la apinión de Mandela, el Pais Vuscon, tan quertido. está gobernado por la engañifa. El PNV ha deteriorado la constitucionalidad que io legitimaba. ETA, a koma por todo, ni abandora la violencia ni deja de protestar politicamente a través dc mascaras como $\mathrm{ttB}$ o EH. Al parecer, sin desarmarse, lodos esperan yue ef olro dé unos priméros pasos que habrian de darse de consune, Los partidos estataley se conforman on una monotonts queja inutil. Los vascos razonables suffen las con secuencias de un triste camaval. a cuya miercoles de Ceniza ertaboran los curas. Todo se vuelve all palos de ciego.

\section{Basta de marear la perdiz: comision de investigación.}

E] PSOE walveri a presen- do con su propia promesa

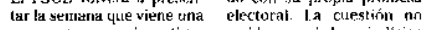

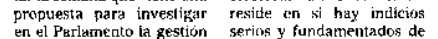

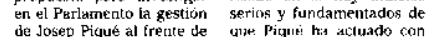

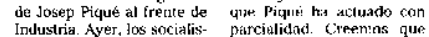

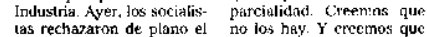

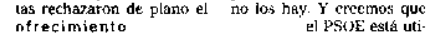
nfrecimiento
del ministro de creat una sub- of the asunto para des conisión parlamentaria pata examinar lodas nes conceriddas nos concedidas incluyendo las mes pyerdo las más polémicas Fimo las de 1U insisten en que quieren una comision en torla regla.
La diferencia enlre una somisibr y una suberom sión no es briladi: la prim ra permite solicicar la declaración de lessligios y extrater conclusiones puliticas, lis sefundd simptertente exa minar documentos. Dado que la inicisliwa parte de los dos prithcipases partidos de la oposicion $y$ que tiener un intrero mul importanie de dè' a su petición, cumpliengestar al Gobier-
too. Pero ello tho justifica la negaliva del PP erear una comicreas una comi-
sión de investigación que las teglas del juego demacriticy exia uposición para que el Gobiternil teng al deber moral de acceder, sean males sean los molives yuse esconda la iniciativa. Pique que reconociú hace yno dedy que tial vez se hab equiviciden at nefarse a conlisfoll, debe inpul war rectificación. La unwestiga cins es la unica altematipa pata disipar ceal quer somhra de sospection shbre. acuach mareat la perdiz. gen. Basta con que la pida

\section{Pujol no quiere. elecciones: anticipadas}

Thos noras y media duró la entrevista de ayer enlte Aanar y Pujwl. A juzgar por las paliabras del presideml. las reluciones entre el pt $y$ ciu pasatr por utra lana de miel. Pujol aseguró que la cualición va a apoyat al Gobseno hasta cl final de la legistallura y que renun -la hasra mor do plantcar nueves reivinatea ciones. Ea sume, vijo nada uye pueda ino hara a Aznar aunce éste no a Aznar, auncue este no se compronetió a agotar la limito a comintear a Pujo que no ha cambiado dé opinión. Pujol, en canthin, ye se ha contrometido a celébrar las aulonomicas en stono. El actetinto a junio de las generales no le haria mingupa tracis. los cual explica el inequivoco apoyo al Cobiemo, que no es sins la expresión palpable de enorme interis de pujol de no poner ningun vbriticulo para que A

\section{DE VUבZTA Y MEMA Milicia}

Llega Serrs: Ejército democrático, misiones solidarias, huracan Mitch, hospitales... Eht, eb, un momento: Cle Trencearl le deria $t$ Grom Handi.ape Gran Handicape, sur domudo. paraplejico ison F $\Omega$ U Oenegés? No se me itevilum bren, porque sí hay que matat, taqui quien mata? rugue pientas,

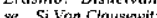
se... Si vont Clalisewit Pú...-ERASMO

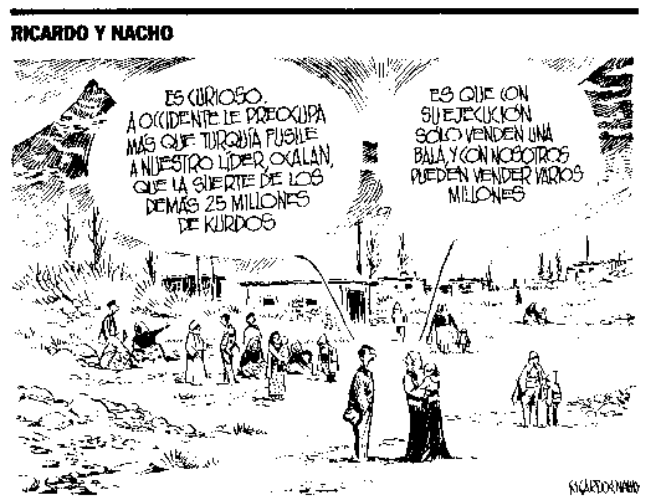

\section{EL $\neq$ MUNDO \\ PAIS VASCO}

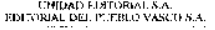

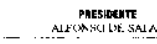

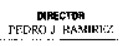

$$
\begin{aligned}
& \text { PIAGCTOO QLWEM: }
\end{aligned}
$$

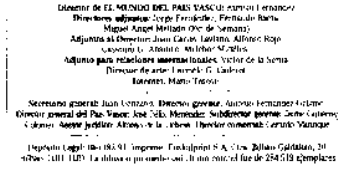

La Peligrosa

\section{DESESPERACION KURDA}

Ea noticia de la detención de Abdulá Ocalan, lider del Partido de las Trabajadores del Kurdistán (PKR). recorrió ayer cono us escalofrio las espaldas de miles de kurdos en todo el mondo, desencadenando la ocupación de casi 30 sedes diplomíticas griegas, manide cuatro persoras, una de jas cuales de cuatro per

ha muerto No esta claro el papel desiemperzado
porGreciay porkenia en laoperación. pero si existen sprios indicios de que el rétimen ture aliado estrategict? de lat OTAN - ha capturado a su pieza ción de los servicios secrostos norte. ción de los servicios

Acaba así el dramático peregrinaje. de Ocalan: ahora se enfrenta a las. de Ocalan: ahora se enfrenta a las. temities condictones de detericion de un pais reiteradamente acusado de violar los derechos humanos, que
practica con frericia la lortura y que practica con treticiá la tortura y que castige eon la muerte el delito de tar contra la integridad del pais.
Probablemente el Gobiemo turca no se atreva a ejectatar a Ocalan. Fero para derrotarlo basta rá con tunbicnerlo confinado en una relda hajo la amr-
maza de que cualquier dia se le puede maza de que cualquier

aplicar la pena capital. Ta detención de (rcalan supone un punco de inflexiñn en el drama del pueblo kurdo, cuya historia se ha escrito con sangre deste que en 192,3 se fir-

reparto de la zona dejó el Kurdistian dividido principalmenie en cuatro jajses (Mra, Turquá, Iran e lrak). Hoy casi30 millonesde pernonas estan despromistas de lon mas chós como puebles

uEspero que la captura de Ocalan sea una solucion al problemiar, atirma et primer ministro turo, Bulent Facrat, entrevistado por este perindico. solo la ceguera politica puede hacer perisar que maritndo al perro se vil a acabar la rabia quelos kn mulado ren bu ano de ricus lis deramente reprimidas. Solo ch los anos te actidad armada del The han muerto 30.009 personas: guemilleros kurdos,

La comusidad intemacional nunca se ba tomadn gran interes por este

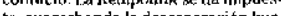
to, exzcerbando la desesperacion kurda. En este contexlo, queda patente is frvolidad del Parlamemis Vasco que. con su invitación unitateral al exillio una compleja madeja de tensiones internacionales $y$, tal wez en una espiral de vintencia

Cobra fuerna, sin embargo, la nesesidud de celebrar una conferencia internacional con los cuatro países afectados para promover una autono. mía kurda. Si nu les ofrece un fulurik. secorre el resgo de que caigan en uns desesperacton tan peligrosa como fue en tiempons la de hos pajestinns. hurda, solo puede verse enredado en

\section{El Psoe no Quiere la Verdad}

Asumir la vetdad requiere valor. Y Parectia por la reacción de Almunia que el PSOE estaba dispuesto a invessliga el pucherazo en las primaries de Já menciado por Manuel Aguilar. Pero los bechos no tardacon en desmentir esos pruposites. Anothe la de militancia a Munvel Aruilar. al que de militancia a Manuel Afuilar, al que acusan de haber cometido tres irregamismo reconoce haber participuds. mismo reconoce haber participado, la partidn y la filtreción de ta denuncia F.L. MUN [M].

Serría cotmp rensible y hastia eliogiatio que el PSOE hubiera suspendido a Aguilat si al mismo tiempo hubiera procodide de la misma forma com Gaspar Zarrias y el rosio de kas persontas que supueslamente interviniction en resulta absurdo es dar crédito a quersion de Aguilar para castiparle y dudar de ella para exculpar a Zarrias que porcierto, yacometio un fraudes or el Sendo hace ocho thin al suplan- lar a un conpañero p

Fn section Fin sepundo lermino, el PSOE cencotrecto: callar el fraude o auloinctsparse en solitario?

$Y$, en tercier lugur, le suspende por haber dado a conocét las irregularida des a un thedio de comunicación. E gesto de la direción no puede ser más cla ro: ya saben loque les espera a quie.
nes se atrevan a sacar a relucir trapos ress se

La retacción del fsot dęmuestro que no solo no hay voluntad de exclis recer lo sucedidn sint bu que se preter de es lo contrario anajar tienta sobre la verdad e intimidar a los militante. que, en el futurt, se juedon sentir ten tados a seguir el njemplo de Aguilar. partidu que propugna una renovación democtática de fachala pero que sigue actuando cen las viejas pranticas de pasado. Y Borrell de oyente. sura a Aguilar haber denunciado a Muy poco o nada ha canjbiado ers un 
Desde la libertad que tiene El Mundo, como cualquier otro medio de comunicación, para defender los puntos de vista que considere oportunos respecto a cualquier tema, no hay nada que objetar. Sí se pueden censurar los mecanismos desinformativos que el periódico utiliza para fortalecer sus puntos de vista y por extensión los del Gobierno del PP. Sin embargo, El Mundo puede defender los puntos de vista que considere oportunos ante cualquier decisión política, económica, social, etc, que adopte cualquier parlamento, asociación, partido político...

Nada que objetar, decimos, excepto la incoherencia del periódico que a raíz de la decisión del Parlamento Vasco de prestar su sede a la Asamblea Kurda en el Exilio comienza a defender unos puntos de vista totalmente opuestos a los que ese mismo diario defendía solamente tres meses antes.

El 17 de noviembre de 1998 El Mundo publicaba en portada una noticia que titulaba Movilización kurda contra la entrega de su líder. Unas movilizaciones que tenía lugar en Italia para reivindicar la concesión por parte del Gobierno italiano de asilo político al líder del PTK Abdulá Ocalan. 

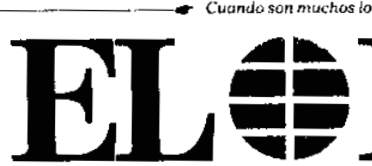

POLEMICA / Condenado a 5 años por vender libıos que minimizaban el Holocausto nazi/29

\section{Borrell pide ser el único líder político del PSOE, pero Almunia se resiste}

\begin{tabular}{ll}
\hline Ambos se comprometen ante los \\
\hline dbaronesm a llegar a un nuevo acuerdo \\
\hline de reparto de papeles antes del sábado \\
\hline Maskin, Jose borzell recono-
\end{tabular}

VALORADO EN 3.500 MILLONES DE PESETAS

\section{Roban en Holanda un cargamento de Viagra destinado a España}

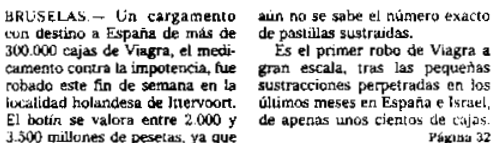

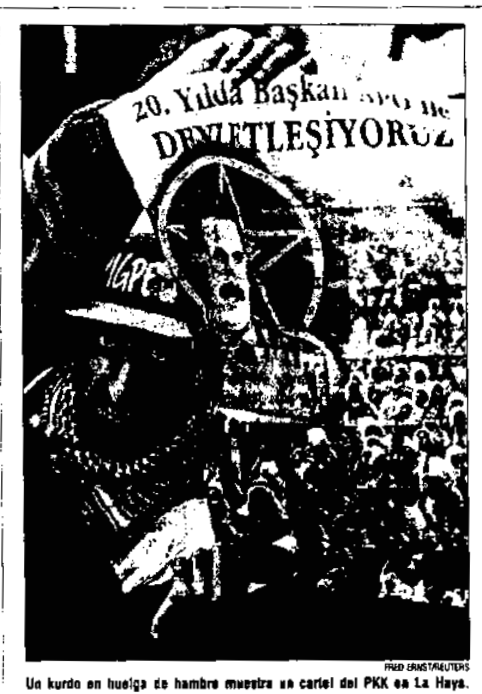

\section{Movilización kurda contra} la entrega de su líder
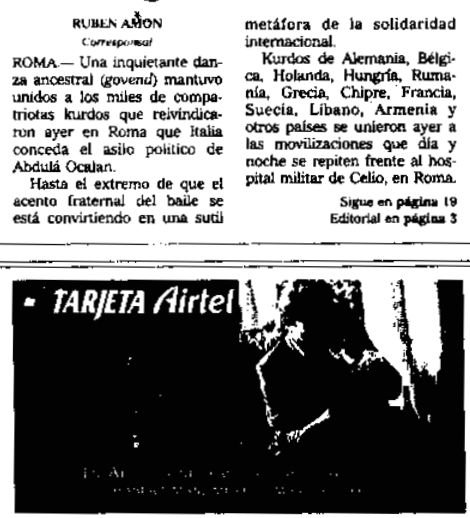

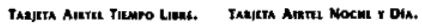

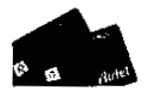

Bipiilis

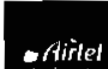

El Cesid espió a dos asesores de Eduardo Serra sin informar al ministro

- Ruliged Bandají y Pedro Argüelles tweron objeto de seguimientad y vigilancia por Caldentin, que sospechaba que podian haher filtrado intomación sobre ula Casa*

Jasel LOEO MADFID-El dirtetor general de Centro Supertor de Información de le Defensa (Cesid), Jevier Cal. deron. ordens a un equipo de agentes esplar a dos de los ases. naxims confianza del ministro Eduardo Serro, dos semanas despues de atescubrirse, en el pasado mes de abril, las eqcuchas ileg ales gue los servicios secretos habian venido practicando en la sede de Herribatasuna (Hi) de Vitoria. Colderón wctuó en todo momenjo espaidas de Serra, su superior ción de espionaje.

Sigue en phigion 13

OTRAS MOTICIAS

EA rechazará la

Asamblea de

Munieipios si

actúa como un

«contrapoder

desestabilizador"

El piloto del avión accidentado en

Melills tenit 0,41 de

aloolvol en sangre

Los constructores

anuncian que las

viviendas subiran

un $20 \%$ en 1999

Dimtte el director general de Aena

antes de ser

destituido

VIVIR AQUI.

Sepl reabre la

privatización de

Babcock Wilcox 
¿Qué importan más: los principios o los intereses?. Así comienza el editorial que ese mismo día publicaba el periódico El Mundo bajo el título Drama kurdo, dilema italiano.

De acuerdo con los argumentos utilizados por El Mundo en su editorial, el Gobierno italiano se encuentra en un notable aprieto, ya que tiene buenas relaciones políticas y económicas con Turquía, un país que forma parte de la OTAN y que sirve de dique de contención del islamismo radical.

El aprieto o dilema al que se enfrentaba el Gobierno italiano derivaba de la eterna paradoja que arrastran tras de sí la mayor parte de las decisiones relacionadas con la política internacional. Si Italia concedía el asilo político a Abdulá Ocalan se enfrentaba al Gobierno turco y ponía en peligro sus inversiones e intereses económicos en ese país. Si no concedía el asilo político a Ocalan y lo entregaba a las autoridades turcas ponía en peligro la vida del dirigente kurdo.

Paradoja que el periódico El Mundo explicaba a la perfección en su editorial. D'Alema -afirmaba- no quiere desairar a las autoridades turcas, pero tampoco puede desoir las denuncias sobre la sistemática violación de los derechos humanos y la represión que el Gobierno presidido por Mesut Yilmaz practica sobre la minoría kurda de origen indoeuropeo. 


\section{LA THONERA \\ ANTONIO GALA \\ La intrahistoria \\ A USA no le corvitent weubar con Sadam Husein. Si tho, ya lo hubiewe hocho. La CIA - que en Irak ge toide por la escalt Richter- sabe bastante bitm to que hace para su beneficio. Sadam eB su hombre en el Proximo Oriente. Ya fue utlizado y lo seguir siendo: menazado, pero amenazante. Las expe riencios USA, en toda clase de patios traseros, siempre sostienen su triterts mas o menos visible. Este, es inaginable. Desce la guerra televisiva de 91 ba llovido macho. Singre, sobre tado. $Y$ horto- res $Y$ hambre. $Y$ dewolucion. Sobre una sola vic- tima el puebla irald. Que acabe tanto borror. No con otro horror mis, pleane.}

\section{El doble raseno de Villarejo indigna a sus companeros}

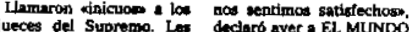
reprocharon dictar sonten uno de los miembras de cias pollticas. Dlferon que Sole. Es comprensible of tormabon parte de uni malestar ante el patente conrpiracion. Les tucharan doble rasero de Vilarejo, de ser agentes al servicho que siempre ade en deten-

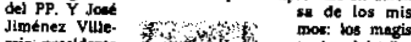

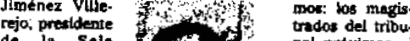

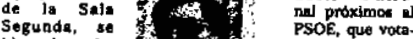
Segunda, se
bizo el sordo. No dijo ni uni ft a a foror de la ino No dijo ni un sola palabrin en

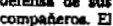
pasesto sabedo. Carmen Rame Carmen Rame gut y sela ver do la misma garrionuevo son cpresos como un proterianal terri politicosen condemados sin blemento respetuous de h prutbosan. lo que equivale " tibertad de expresion. Si zo acusir a sus jueces de pro- critican las decisiones de varicacioth- Tampoco dijo Bselgalupo y Ancos -o

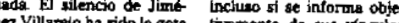

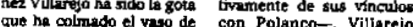
gue he calmado el vaso de con Polanco-. Viliarejo a paciencit de jor siete copins publicamente que es

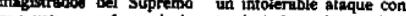
que wotron a hoor de la tra la independercilu de lis

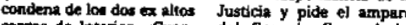

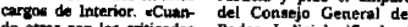
do otros won lor criticadas Poder Judicial. ise har se renccions de fortiti ifapi- complice el Consejo de un

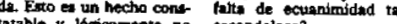

Pachono y recto

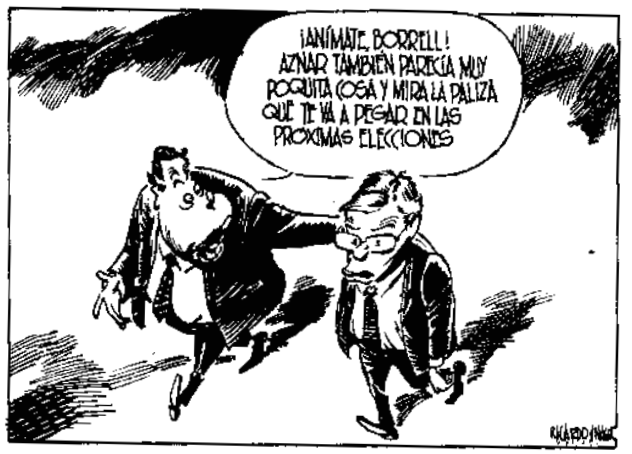

\section{be centrismo imposible con este Cesid}

51 Cosid expia, sin cominictrelo al Gobiemo, a dos Altos coleberadorer de que corpech autore que poidin neas sobre la vigilantin de $L$ sede de HB en vitorte 1 moticla surve de recordatorio dar, rancione en el abxos de poder y de th ingalidad, de

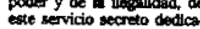

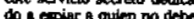
Rocuend tamblen el debe onra un Gobleten el acsat

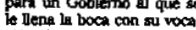
cion de centritsmo reformis ta, pero que ón deb denostrario en la pration polftice con una serse de medils sigrificatuma, un de las mas importanter seri la radical refurtinción de un

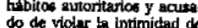
do de vishar th intimictad do ser eustizuido por otro estrictamente por otro, mareo jutidioo propio de una deinocrisia praprad Iso of que zeria reformismo.

\section{DE VIZTA Y Mank}

Trueba

La sartriana níta de sus ojos, de uno de ko pocos bizcos aproxque se covocen. Gano que Ge canocen. Gans Wider exribio el Des. ta sobre aquel guion de beatie, embromador $y$ agnórtico $-Y$ dort't beliove in God-al scepechar que al justiciero Jehovd acuso es Brande en el Sinns. Un septor, te pergó la luz, dador $y$ se fye a sh cash TERASMO que coro Equardo Serta por servicio plagado de viejo teronomio y aúr medi. se enoendio el acomo-

\section{BORRELL MERECE LA OPORTUNmAD Que Gano EN LaS PrimarLas}

Los dirigentes del PSOE se debaten hace semanos en uns duda que rectuerda mucho a ta del bolero: 25 pueden tener das lidetes a la vez y no estar loco' La bicefalis puesta en mar cha despubs de las primarias, con el secretario general $y$ el candidato a la Pressdencia del Gobierno compartiendo el protagonismo politico h resultado un tracoso estrepltoso.

Sed jorque en Espants no existe la tradición en los pertidos de asumi responsabilidades en compahla o por Ja incomputibilidad personal de Jor guin Aluuna y Jose Borrell, to cleto th que los gocialistas ostent, ho clecto vivir. Despuibs de has primarias, ron a un pacto que deposito en en ron a un pacto que deposito en Joaquín del PSOF con el presidente de? Gobiemo y el costo el presidente de Gobiemo y el resto de las liderea poilticos, ㅁitentras Jose Borrell tera bl lider social que recorria Enpaha habind de los problemas de los ciudadanos. Pers, iayl, en extos messes, Borrel $3 \mathrm{e} \mathrm{ha} \mathrm{dido} \mathrm{clienta} \mathrm{de} \mathrm{que} \mathrm{al} \mathrm{secretario}$ Reneral sociplista lo habla tocedo fo parte del leán. La treguo de ETA y otras cuestiones polfticas convirtie ron de pronto al preaidente de Gobierno en referente imprescindble. $Y$ ast, ironias de la vida, low do lideres socialistas -que tanto han insistido en la falta de talla polftica de Jose Morta Axnar- se empezaron pelear por ser los intorlocutoras de jefte del Ejecutivo y del resto de los cuenta de que fue dempesiado condes- cendiente fll cedor efta tarea wl secre-

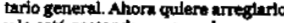
$y$ lo esth costando porque el correaso Almunia se rosiste por der su brazo a torcer. Ayer, Borrell Gio s entender que quiere ser ef unico lider del partido por la sercillin razón de que gand las primariag.

Algunos bocializas ya se habían Percatado antes, cotho el dirizente critico Antonio Garcla Santermases, quien el pasado mes de octubre reconoctó que fueron unos insenicos jos partidarios da Borrell qut renunnis ran a un Congreso extraordínario desputs do las primurias. El candidato perece dertes le razos abore pero como ya es demasiado tarde para

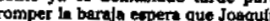
Almunin entro en nzón y in ceda al protagonismo politico.

Los berones roglonales han tercio. do en la polbmicter exigiendo unt blce fallis pacfico pare poner tin al enpectúculo de palea permanente aue est dando ef PSOE. Iq única soludión este onfrontamiento es que ef recre tarto gonerol de los sotialistes ced terreno en twvor del candidato. Almu nis y Borrell te hen comprometido encontrar une colución antes de śbado. Mta vale que lo consigan no quieren que el principal pertide de la oposicion sirga apareciendo ante lo ophion publica como una julifde los mats preccupedos por sus cuita internas que por ofrecer alternativa al actual Goblemo. Les van er ello gus opcione: de txito o fraceso on las proximas elecciones.

\section{DRAMa KURDo, DREMa ItallaNo}

ique importan min: los principios o los intereses? De fa respuests a esto pregunta depende la decision del Gobierno italiano sobre la extradición a Turquig del lider kurda, Abdula Ocalan, det

El movimiento kundo en Europa se ha movilizado estos dies para pedi que Ocalan no sea entregado il tifgithen de Ankara, que le ucusa de ser el cabecilia de una organizacion tertoris ta, ea PHOK, que ha cassado miles de muertos.

El Gobjemo italiaro se halla en un nosable aprieto, ya que tiene buenas relaciones politicas y económicss can Turqufa, un pais que forma parte de la OTAN y que sirve de dinue de contención del islamismo radical.

Elprimer ministro O'Alemenoquiere desairar a las autoridades turcas, peno tampoco puede desois las denuncias sobre la sistemática violación de los derechos humanos y da represión que ol Gobierno presidido por Merut Yilmaz prictica nobre la mingria kard8, de ortigen indouriopeo.

No hay dud de quo Ocalan es el res ponsablie de arentados en los que hat muertoclentos de inocentes, perotam bién es ciestoque el rétimen turcoest lievando a cabo un inmord y cruel gernocidio de las kurdos, que habita en la parte arientol del paif. Mas de 3.000 putbiod y aldeas destruidos cerca de tres millones de refuriados es el bafance de la política de sanare fuego. Suena, pues, a sarcustro que of Gobiemo torco dige ahors aue que sbolir la pena de muerte.

Si de nuevo prima la realpoliak, seguro que Oeslar seŕs entregado a sus verdugas. Si el Gobiemo italian opta por el dificil camino de los principios, debe ser respaldado por todos sts sonsoc buropeos, que pueden hace mucho part aliviar el sufrimiento de putblo kundo, arrojado al basurera de 
Paradoja que el diario no dejaba resuelta, pero apuntaba su punto de vista favorable a optar por el camino de los principios, a pesar del coste económico que esa postura pudiera arrastrar, tal y como explica en la primera frase de su editorial.

Si de nuevo prima la realpolitik, -afirmaba en su editorial- es seguro que Ocalan será entregado a sus verdugos. Si el Gobierno italiano opta por el difícil camino de los principios, debe ser respaldado por todos sus socios europeos, que pueden hacer mucho para aliviar el sufrimiento del pueblo kurdo, arrojado al basurero de la historia.

Para El Mundo formaba parte de los principios la solidaridad con los kurdos, a pesar de las presiones económicas y las buenas relaciones comerciales de Italia con Turquía. Es más, reclamaba la solidaridad de los socios europeos para hacer frente a las presiones económicas que pudieran surgir por parte del Gobierno turco.

El Mundo no dudaba en reclamar la solidaridad y situarla dentro del campo de los principios cuando su posible aplicación estaba en manos del Gobierno italiano, pero no duda en cambiar radicalmente de registro cuando es el Parlamento Vasco el que adopta la decisión de prestar su sede a la Asamblea Kurda en el Exilio.

Además, a través de los argumentos que utiliza en uno y otro caso, $E l$ Mundo deja bien claro que el fondo, tanto en una como en otra decisión, no son los problemas económicos que se pueden derivar de la medidas. También el Gobierno Vasco, o el español, podría reclamar a sus socios europeos la solidaridad suficiente para hacer frente a las presiones económicas que pudiera imponer el Gobierno turco. El argumento de la solidaridad económica tiene la misma consistencia para cualquiera de los dos casos.

El problema fundamental, a pesar de la reiteración con la que El Mundo trata el tema de las consecuencias económicas que pueden derivar de la decisión del Parlamento Vasco, no está ahí. El Mundo utiliza las consecuencias económicas como una pantalla para ocultar las verdaderas razones de su negativa.

Los problemas económicos, tal y como argumenta en el caso de Italia, aún siendo importantes no son determinantes. Los argumentos definitivos los encontramos, pues, en aquellos de carácter estrictamente político: el Parlamento Vasco no tiene competencias, es una bofetada a Aznar, representa un paso más en la radicalización del PNV, etc...

Los argumentos de El Mundo aparecen así en clara sintonía con los principios defendidos por el Partido Popular y el Gobierno español sobre este tema, de ahí que no dude en afirmar que la decisión sólo se mantiene desde el punto de vista de que representa una bofetada a Aznar.

Ante un tema conflictivo como el analizado, El Mundo se muestra partidario de la defensa de unos puntos de vista que coinciden o están en sintonía con los defendidos desde el Gobierno, a pesar de la incoherencia que demuestra al defen- 
der su nuevo discurso.

Además, la posición adoptada por El Mundo ante el acuerdo solidario con el pueblo kurdo aprobado por el Parlamentario Vasco es cuanto menos contradictoria con los principios editoriales que según Pedro J. Ramírez defiende su periódico. En una de sus cartas del domingo, publicada el 29 de noviembre de 1998 y titulada La camisa de Doan Viet Hoat, Pedro J. Ramírez, refiriéndose a la política informativa mantenida por El Mundo en sus primeros 10 años de existencia afirma lo siguiente:

Yo no maldigo la poesía concebida como un lujo cultural por los neutrales, pero sí creo que cada vez que se vulneren los derechos humanos más elementales estamos obligados a tomar partido, partido hasta mancharnos. Así lo ha hecho el diario El Mundo durante su primera década de vida, aún incompleta y así lo seguirá haciendo, con radicalidad y serena coherencia, les incomode a quien les incomode. 


\section{La camisa de Doan Viet Hoat}

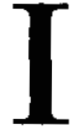

ncheso en el calismecopin de razas, chllurds, lenguas y retigioney del Beinat reconsinuidn hacian una extrádia parejia. tin negro $y$ un chinu. IIn gordo $y$ an naco. Un allo y un bajo. Un Lemationo destiogtado y uII ticia que nuestru homenaje ol de la Junta Directiva de lis Asocisción Murndisal de heriogliços reunida en el Ífbano- les hermeatara, puesto que la opresion y cl sufrimienta ya lo habisit hecho antes.

Lós lectores seguramontc habran seguido la odisea del brawo Piug Njasse. director de $t e$ Musisager de Camerín. deside que incurrin en el irtinlerable desaffo de publicar on su peribchicos que el presidente Pan Blya habla sufnto una indisposicinin durante un partido de

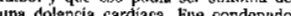
dos años de chroul por the tritunal que

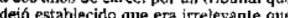
la notici - injuriose para Estado-fuera diena o no y le armojaron a la más intrutuda celda yo un perial de pesadilib. Su Ienté, con grilleces en las pies, posando entre ladrunes y asesinos hacituados a sta alrededor, tmbutida en unta camiseta rewindicativa de lis thertad de expresiona dio la vuella al thundo. conmovió al propio secretario pereral de a. ONU Koll Arman y cont ibus at st puesta en liberad anticipade.

Vestido ahorra con una elc-gante tinicio celeste con hurdados de ceremonial, Njawe me cuenta entre carajadas cómo cuapdo empezo a rnandár à periódico articulos desde la carrel, suk guardianes le diferon que eso podía trautre kprotado corro un animal en aquel agujero insalubre! uLes conlestré que zunque nn habie cometido njoggún delito portian tenerme fisicamente encarkelado, pero nunca lograrian que espiritualmente the cotsiderara un prisionerum.

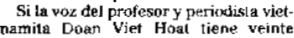
veces menes decibelins que la del exu. berante y archisimpático Nja wo, tal wex sea a 10 mejor porque ha pasado veinte veces mass Liempo encarceladto. Siendo un jowen vicersector de la Universidad de Saigon se distinguío ya pur sus criteas a los gobientros marioncla de joh corteaniencicanot, pero fue el régimetr Y la unifiación an el dif de la guerira Al cabo de dus periodos oue disidericia. de veinte sinos entre rejas solo unat intent. sa campana intemasional a su favor. tras la concesion este ano de la Pluma de OTO logró que los gobernantes de
laanoi le pusieran en libertad a cassbio de obtigarle al exitiv

Hnal, que vive ahora en Estados Uni. dos, recordaba en Beirul las terrible condiciones de su régimen carcelario. Recluido durane cuatro años en una cel. da de tastigo, térith estrictamente pro
hihyido disponer de papel y lápiz. Por esto pasaba las hores hablando consigor mis. mo, practicándor idiom âs y com:poniendes poethas de menoria. Una vez, unus cuartillas y boliertito por ei ventanuco de ta celda para que puctiera denunciar las condiciones del penat. $5 u$ unseriur lleEo al exterior, pero a el he certaron a cal y canto ef ventanuco. Como el calchr se hiza enlontes insuportable, Hal se

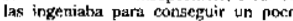
de humedad, mojandn sul camisal en agua y colocándola en lat pared. Fta tam-

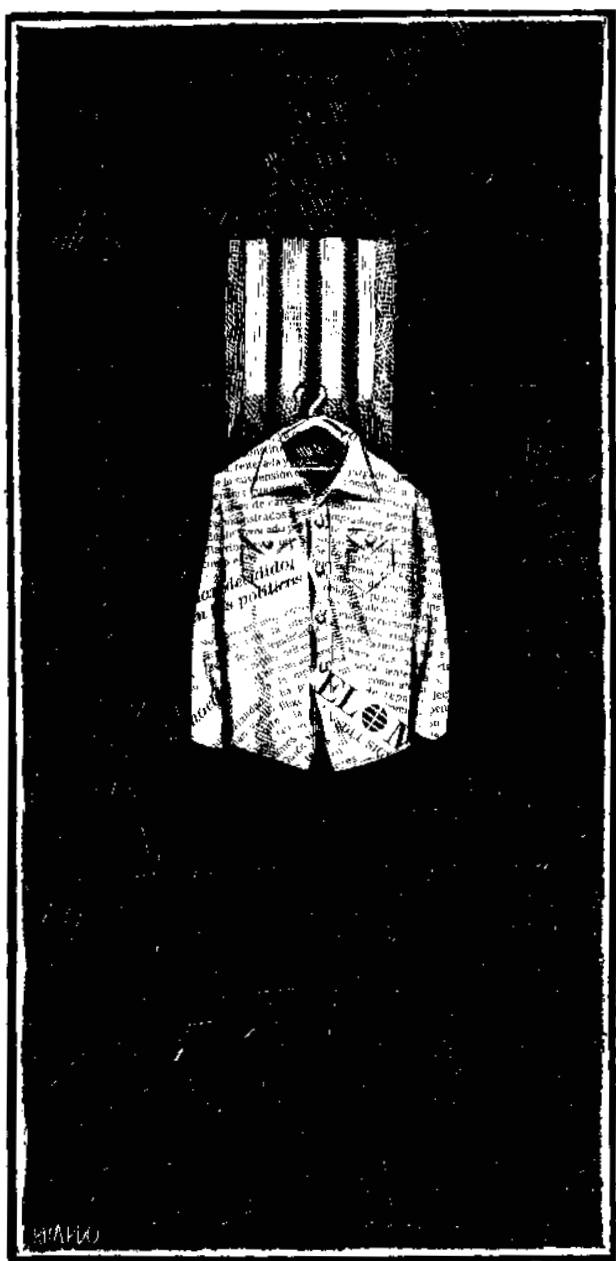

RICAREOK MARTTNF

ta. Al cabs de varios dias aquella camisa periodistas permanecen encarcolados en desplegad extendida con los brazos los más diversos lugares del mutnd

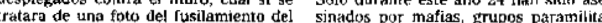
honabre invizinle no pudo por menos Ies a sicarias politicos. Son el simbolo que llames la atención de las carceleros. de csos miles de activistas quc en este "Yo las expliquá que aquello cra mi sis. emblematico cinchentenario de la Decla le mis de aire acondicionado y ellos se racion Untiversal de los Derexhos Hum

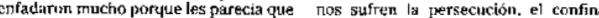
era una mane rid de hulmillat a su Gabjer- miento y til exilio por atreverse a pxpremon, me explica Hont con una senrisa sar'se librementhe.

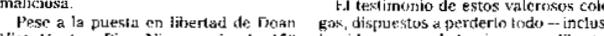

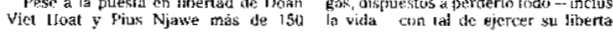

y Ilenar do contenida da de tes demás. debc de servirnos de aciliate a quiefues al neriodismo en un pais, imperfecto, pero demericico. Las myres ineomo pera demucratico. Las mayores ineorlor
di.dados o vilezas yut hays podido acarreat acarreatihis muestras revelaciones $y$ cenunclas, quedan obsiamerte diluidas estos 0 el de la brara Gap Yu que sigue mantenienctio el putso de la no retrac. ticion con wus implacables carceleros

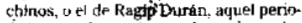
dista y iraducior turco al que las autaridades de Anttára - ya que no pueden Irjucar al lider kundo- han encárcelado por cntrevisidr' a Oeztarn, o el de tantos otriss que en Cutw. Nigene, Irát, Sctia - Biefornusia tratan de cutaplis con su whyligacign contra el viento del fanatismo y la marey de ta opresion.

Todo phydico es un proyecto ittelectuat, $y$ por lo lanto polfico en el sentirdo más roble de la patabra. De wobra sabemus lo que significabe en la Extraña de hace 110 crarto de siglo decharatse apolítico. Yor $n^{t}$ maldigo in postia con. cehida como unl lujo culural por los neutrales, pero is creo que cada vez que elementales asta mos obligadas a tomar

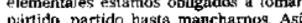
pistlido, partido tists manchamos. Agt le sis prithera decada da the ún Ie sis prithera decada de vida, aun incompleta y asi lo segura haciendw. incomotc a quien les incotnode contra F:TA y concra el GAL. Contra Pinnchet $y$ contrs Castro. Contra los butus y con ira los tutzis. Contira la limpieza étnica de los serbios y contra lu de los croatas. Contra la cleptocracia de derechas y contra la que se dice de tzquierdas. ConIra ta Tocmenta del Desierto y contra todo tipo de ayoluks, fatwas y yihuds. ia Historia del sigto reinte puede resumirse toptho la del triunto de la
sociedald de la informacion srbbre la culsocjedjad de la información srbbre la curtura de los totalirarismos. En casi tndos los confines del globa, la ulima generello dir de pretsa auxiliacla por comna midables. La experiersia española firma todo ecto tanto en el mind conen el corlo plazo y a los furndadores de EL MUNDO hadie podrá ambarames el orgullo de haljer contríbuido en une encrueinada decistra y que lon ciudadaciaides.

mos por delante ef reto de bacer cuda dia un periodico rias completo rigurest, capaz de groporeicuar a un pliblict cada vez mas preputtajo y exigente, las claves para interpretar realiLades comphejas. EL MUNDO tiene que ser el gran aliario europeo de calidal que siempre hamos sonado. Para enta gene ración $y$ parta las siguientes. Al ntertos porque para que un periódion se consulide y arraigue de verdad tiene que ulur por encima de las personas Sin el respaldo de nuestros actuales accio niskas difivilmerute habriamos llapado tan lejos a al menos tan pronto: $y$ el compartir este provecto con ran rievo grupo caracterizado también por so anrije empresarial y pot su extraordiraria solvencia en el sector va a ser des. de ahot al mejor de los estimulog. Pero que hadie terga la menos duda: cada FeT cuc sea necesartio, la camisa volverá estitar desplegada sebre al muto.

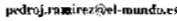




\section{II.- Romper con la mediación: El caso Setién}

\section{El papel de la Iglesia vasca. Recorrido histórico}

A lo largo de los 20 años que José María Setién cumplió al frente de la diócesis de Donostia se convirtió en un líder carismático para la comunidad católica vasca.

Desde el mismo instante en que se hizo cargo de la diócesis guipuzcoana abogó por la reconciliación de los vascos y la pacificación, actitud que le sirviótanto para ganarse el respeto de unos como para convertirse en el centro de las iras de otros.

Nunca ha dudado a la hora de hacer públicos los puntos de vista que consideraba oportunos desde una perspectiva cristiana para buscar vías de solución al conflicto vasco.

Quizás precisamente por eso su vida ha estado plagada intermitentemente de fuertes polémicas y escándalos, provocados en ocasiones intencionadamente por sus detractores para minar la influencia de su discurso.

Ha sido centro de encendidas polémicas cuando ha afirmado que con ETA no se puede acabar sólo con medidas policiales y ha reclamado salidas negociadas al conflicto vasco.

En numerosas ocasiones ha sido centro de las críticas de la prensa más conservadora. Así, ABC le ha acusado de temer a ETA e incluso le ha dedicado una portada en la que aparecía Dios señalándole el quinto mandamiento con la frase No matarás.

Fue también duramente criticado por algunos representantes políticos e ignorado por sus superiores jerárquicos cuando solicitó la creación de una provincia eclesiástica que incluyera a Navarra junto con el resto de las provincias vascas.

A lo largo de los últimos años y en reiteradas ocasiones se ha ofrecido para mediar en el conflicto vasco y buscar vías de entendimiento. En octubre de 1996 Ricardo Blázquez, obispo de Bilbao, y José María Setién, obispo de Donostia, se ofrecieron para mediar en la pacificación del País Vasco. Un ofrecimiento que levantó fuertes polémicas y el rechazo de representantes de algunos partidos políticos.

Su última intervención antes de la tregua decretada por ETA fue en febrero de 1997. Bajo la dirección de José María Setién la iglesia vasca debatió un documento en el que se pedía el diálogo entre el Gobierno y ETA "sin que se orille ninguna cuestión, incluida la autodeterminación".

Todas estas intervenciones a lo largo de los años hacían pensar tanto a políticos como a profesionales de los medios de comunicación que la Iglesia vasca estaba llamada a jugar un papel importante de mediación y de búsqueda de soluciones ante una eventual negociación entre el Gobierno y ETA. En ese hipotético marco intermediador, Setién era una pieza clave. 
De la importancia del papel que la Iglesia vasca estaba llamada a jugar ante una posible negociación entre ETA y el Gobierno da buena cuenta el hecho, posteriormente conocido, de la presencia de monseñor Juan María Uriarte en el único contacto mantenido entre ELA y el Gobierno del Partido Popular durante la tregua.

El 6 de noviembre de 1999 El Mundo publicó en sus páginas que el obispo de Zamora, monseñor Juan María Uriarte, que había participado como mediador en el único contacto formal mantenido entre ETA y el Gobierno en una reunión celebrada en mayo del 99 en Suiza, daba por finalizada su intervención.

Juan María Uriarte adoptó esa decisión porque, según afirmó, se sentía molesto por la publicidad que se le había dado a su gestión y porque estaba convencido de que había sido seguido y vigilado durante sus gestiones para mediar entre el Gobierno y ETA.

El Ministerio del Interior, a través de un portavoz oficial, aseguró rotundamente que no había dado ninguna instrucción para que se celebraran esas labores de seguimiento.

Sin embargo, lo cierto es que el 1 de agosto de 1999 la policía francesa detuvo a Jokin Etxebarria, que hacía de intermediario entre el obispo y ETA. El Ministerio del Interior afirmó que la detención se produjo merced a un control rutinario, aunque siempre se tuvo la certeza de que Etxebarria estaba siendo controlado desde que jugó ese papel de contacto entre monseñor Uriarte y ETA ${ }^{2}$.

\section{La Iglesia vasca tras la tregua de ETA}

El 18 de setiembre de 1998, dos días después del anuncio de tregua decretada por ETA, los obispos de Bilbao, San Sebastián, Vitoria y Pamplona-Tudela hicieron pública la postura de la Iglesia católica vasca en el deseo de que la tregua fuera el comienzo de una renovada voluntad de reconciliación cada vez más plena, dentro del pluralismo y del respeto a las diferencias legítimas propias de la sociedad vasca.

(2) El 14 de enero de 2000, finalizada ya la tregua de ETA, los medios de comunicación publican la renuncia de José María Setién como obispo de San Sebastián, después de 27 años al frente de esa diócesis. La decisión fue acogida con alegría por el PP y el PSOE y con alabanzas de PNV, EA e Izquierda Unida. José María Setién había presentado ya su renuncia varios años atrás. En enero de 1995 presentó su solicitud de sustitución a la Santa Sede, aunque con la condición de que se tuviera en cuenta su criterio a la hora de nombrar a su sucesor.

Finalmente, el 9 de diciembre de 1999 el Vaticano le anunció que estaba dispuesto a aceptar su renuncia, dado su estado de salud y su complicada situación al frente de la diócesis donostiarra. La renuncia de Setién se aceptó finalmente el 13 de enero de 2000, al tiempo que se hacía público el nombramiento de Juan María Uriarte, que hasta esa fecha ocupaba el cargo de obispo de Zamora y que había participado en los contactos entre el Gobierno y ETA. 
El 19 de setiembre la prensa escrita diaria se hace eco de la postura de la iglesia vasca. El Mundo publica la información en la página 11 en un texto que titula Los obispos vascos piden a los políticos altura de miras y flexibilidad ante la tregua de ETA. Sin embargo, lo más significativo de este diario lo encontramos en la página 3, en un editorial titulado La iglesia y la paz vasca.

El editorialista de El Mundo no escatima elogios para explicar el papel jugado hasta esas fechas por la Iglesia vasca en su intento de búsqueda de vías de encuentro. Alaba el esfuerzo tenaz de la Iglesia por no romper amarras con ningún sector del pueblo vasco, incluidos los que se sitúan en la órbita del abertzalismo radical, al tiempo que, según argumenta, ha sabido también contar siempre con el respaldo y la comprensión del conjunto de la jerarquía católica española. 


\begin{tabular}{|c|c|c|c|}
\hline \multirow[b]{2}{*}{$\begin{array}{l}\text { La gestación del } \\
\text { alto el fuego }\end{array}$} & \multicolumn{2}{|c|}{ EN EL PRIMER DIA DE LA TREGUA INDEFINIDA } & \multirow[b]{2}{*}{$\begin{array}{l}\text { EI Gobiemo y la } \\
\text { nueva Galeusca' }\end{array}$} \\
\hline & $\begin{array}{c}\text { ¿Cese de la } \\
\text { akale borrokay? }\end{array}$ & $\begin{array}{c}\text { La inoportunidad } \\
\text { de Berejo }\end{array}$ & \\
\hline 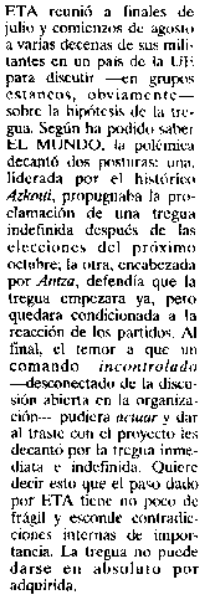 & 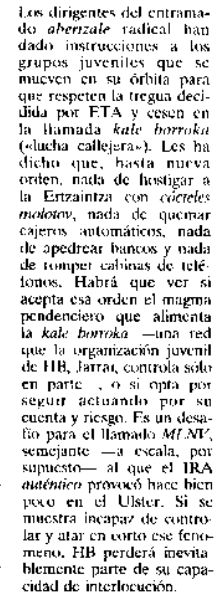 & 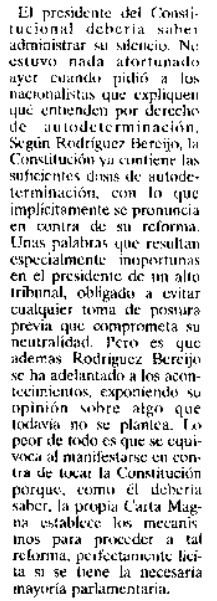 & 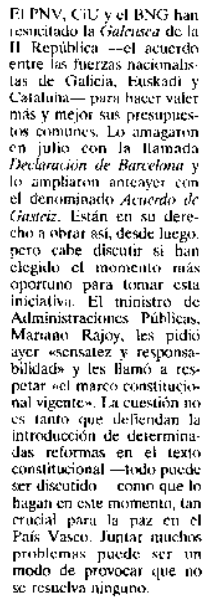 \\
\hline
\end{tabular}

\section{IDHCORAS Y PACHI}

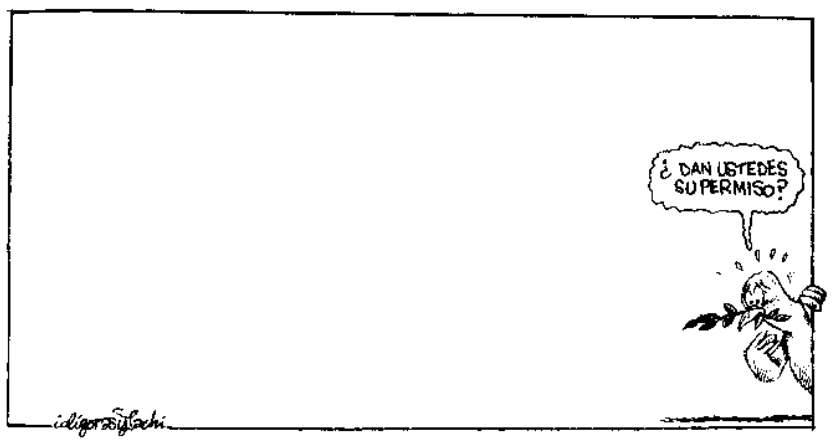

Plaza puBlica

CAMMEN RIGAIT'

\section{El regalo de boda}

$\mathbf{U}$

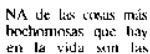
hodas. lincluadas: Iixs pripias. El

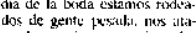

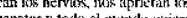

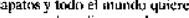

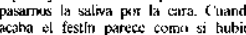

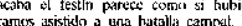

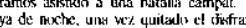
sc abale sibre noworren ta solectad on

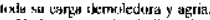

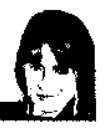

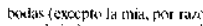

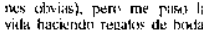
que as peser seguin la gente

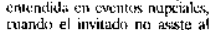

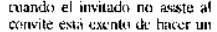

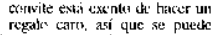

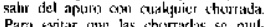

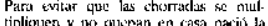
lista de tuodis, una ider priclica que

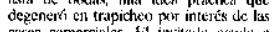

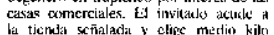

dt: wajillia creycitter que contriltupe a ali-

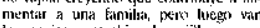

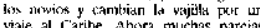

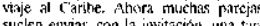

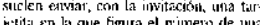

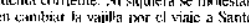

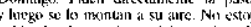

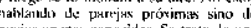

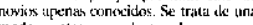

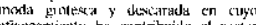

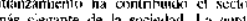

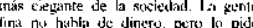

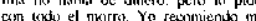
Ifictica. Chliandón rite manctan una imi-

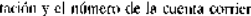

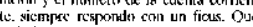
sis: jewlan

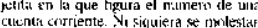

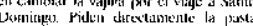

\section{EDITORLAL}

\section{La Iglesia $y$ la paz vasca}

Eus ubichos de las dioressis de Vituria. Bithao.

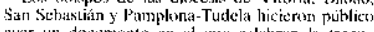

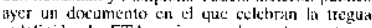

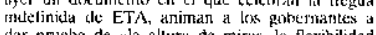
dat prueba de wa olluta de miras. Ja flexihilidad

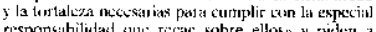

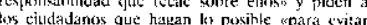

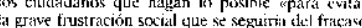
do lias expectetivas suseit walas

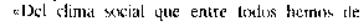

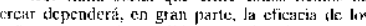

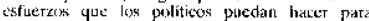
legrist lia meta de: la parificación: afiman. No 4. unis trase relirica, sine un my atisado apunte.

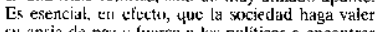
cill ansia de par y luerec y bis prliticos a enconttat

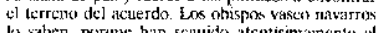

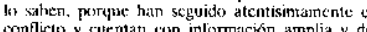

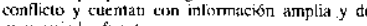

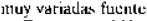

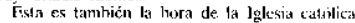

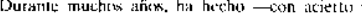
sentido ble la rophturidad desiguates-

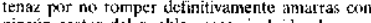
ningún sector del pueblo vasico. inteluidas las a we silúar en la órbita del ahertzafismo radical. It

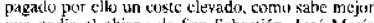

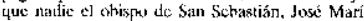

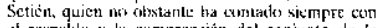

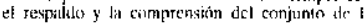
jerarquía católieñ española. A ello contribuyi do manera des iciva yluien fuera hasta el pasado mos

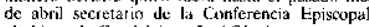
al obispo de Guadalajara, Jorse Sinchez.

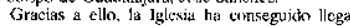
al momerth presente en exueturtes condiciones

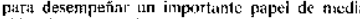

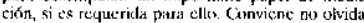

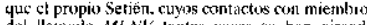

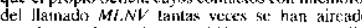

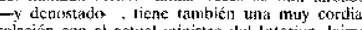

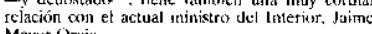
Maypos Oncju.

La Iglesia cuenta con urla wentajit aniadjda on tolc. terrentw al carceer de intereses eluclotales que pucdam irscrferis en cul latsos, cretsnto haga o deje de hacer quedara libre de cualquer sospopicha de partidismn. Ex un valioss gasantía. A to que debo añadirse la auloridad moral que sus aclos tienten

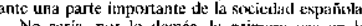
No seria, par lo klcmas, la primera ves en Espana de cotes ultimus decenios que la lglesia

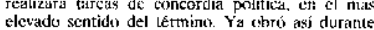
lat transición entré el franciuismo y la demoracia, de la mano de nontieñor Enrique y Tianancón.

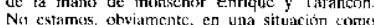

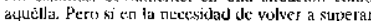
into nnerosir ahstikculo dic iatolctancja.

\section{ELEMUNDO}
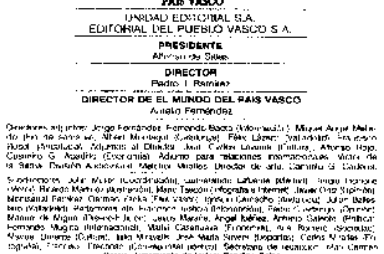

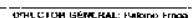

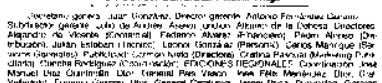


Según este periódico, la Iglesia, y más concretamente José María Setién, han conseguido llegar al momento presente en excelentes condiciones para desempeñar un importante papel de mediación, si es requerida para ello.

Los argumentos que utiliza el editorialista para defender este punto de vista son los siguientes:

1. Setién tiene excelentes contactos con miembros del llamado MLNV 3 .

2. Tiene también una muy cordial relación con el ministro del Interior, Jaime Mayor Oreja.

3. Al carecer de intereses electorales queda libre de cualquier sospecha de partidismo.

4. Sus actos tienen autoridad moral ante una parte importante de la sociedad española.

5. No sería la primera vez que en España la Iglesia realiza labores de concordia política.

El 5 de noviembre, El Mundo publica en su portada que Aznar reclama una respuesta al Movimiento Vasco de Liberación y advierte en ese mismo texto que los contactos, en caso de producirse, tendrán lugar sin intermediarios ni intérpretes; es decir, por un lado el Ejecutivo y por el otro el interlocutor designado por el MLNV.

En un editorial pequeño (glosa) que publica El Mundo ese mismo día titulado Los primeros movimientos de la partida entre Aznar y el MLNV, este periódico destaca que José María Aznar ha puesto interés en fijar unas reglas generales de conducta y cita expresamente que no habrá por su parte ni intermediarios ni intérpretes -está claro que piensa asumir la dirección del proceso personalmente y en detalle- y se propone actuar con transparencia, consenso y cooherencia.

El sábado 7 de noviembre El Mundo recoge en su portada un titular en el que se afirma que El Gobierno aceptará cualquier interlocutor designado por ETA y remite su información a la página 6. En un texto titulado El Gobierno asegura que no vetará a ningún interlocutor propuesto por ETA, el periódico recoge unas declaraciones del portavoz del Gobierno de Madrid, Josep Piqué, en las que afirma que el Gobierno no pondrá condiciones previas respecto a las interlocuciones.

Curiosamente, ese mismo día, en un editorial pequeño (glosa) publicado por El Mundo en su página 3 titulado El Gobierno y la interlocución de ETA, el

(3) El Movimiento de Liberación nacional Vasco (MLNV) lo compone todo un conglomerado de organizaciones políticas, organismos populares, culturales, etc. que orbitan ideológicamente alrededor de los postulados de ETA y en el que Herri Batasuna constituye uno de sus vértices fundamentales. 
editorialista de ese periódico pasa a matizar las declaraciones realizadas por Piqué con el argumento de que es necesario evitar equívocos.

En ese editorial el periódico asume el papel que correspondía, en cualquier caso, a algún miembro del Gobierno de Madrid o al propio presidente y pasa a rectificar y matizar las declaraciones de Josep Piqué.

Así, El Mundo afirma lo siguiente: Es evidente que el ministro portavoz, Josep Piqué, quería mostrar la amplitud de la predisposición del Gobierno al diálogo cuando afirmó ayer que el Ejecutivo no pondrá condiciones previas respecto a la interlocución con ETA. Pero corrió un peligro: que se interprete quería decir que el Gobierno está dispuesto a dialogar con quien quiera que ETA proponga como intermediario, sea quien sea. No es así. El presidente del Gobierno ya ha dejado claro, por ejemplo, que no aceptará bajo ningún concepto mediadores venidos de otros países, cuya presencia pudiera contribuir a internacionalizar la negociación, algo que el MLNV desea vehementemente. Puede parecer un matiz, pero tiene su importancia. Va a ser necesario acostumbrarse a los matices en los próximos meses: suelen ser claves en este género de negociaciones.

El 21 de noviembre El Mundo publica en su apertura de portada una información titulada Setién se ofrece a los presos de ETA para ayudar al proceso de paz. De acuerdo con la información publicada por ese diario, que utiliza para identificar a la fuente de información la expresión "según ha podido saber El Mundo", el enviado de Setién trasmitió al miembro de ETA Jon Gaztelumendi la disposición del obispo de San Sebastián para participar activamente en el proceso de paz, tal y como explica ese periódico en el texto de su información. 


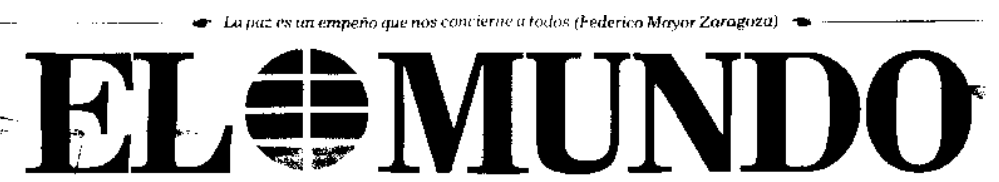

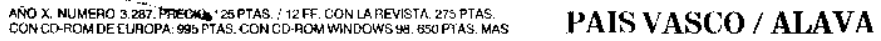

TEL SILLONEANTIUNO

DINERO/Comisiones Obreras lanza su propia tajjeta Visa de acherdo oon Caja Madrid/49

\section{Setién se ofrece a los presos de ETA para ayudar al proceso de paz}

- Logró que el director de Instituciones Penitenciarias autorizara a six colaborador, el sacerdote Fúlix Azurmendi, visitar a Jon Gaztelumendi, utho de los pottavoces de los prescss chitac se compromete con Aznar a modificar al mistmo tiempo que España su política con los reciusos de la batida armada.
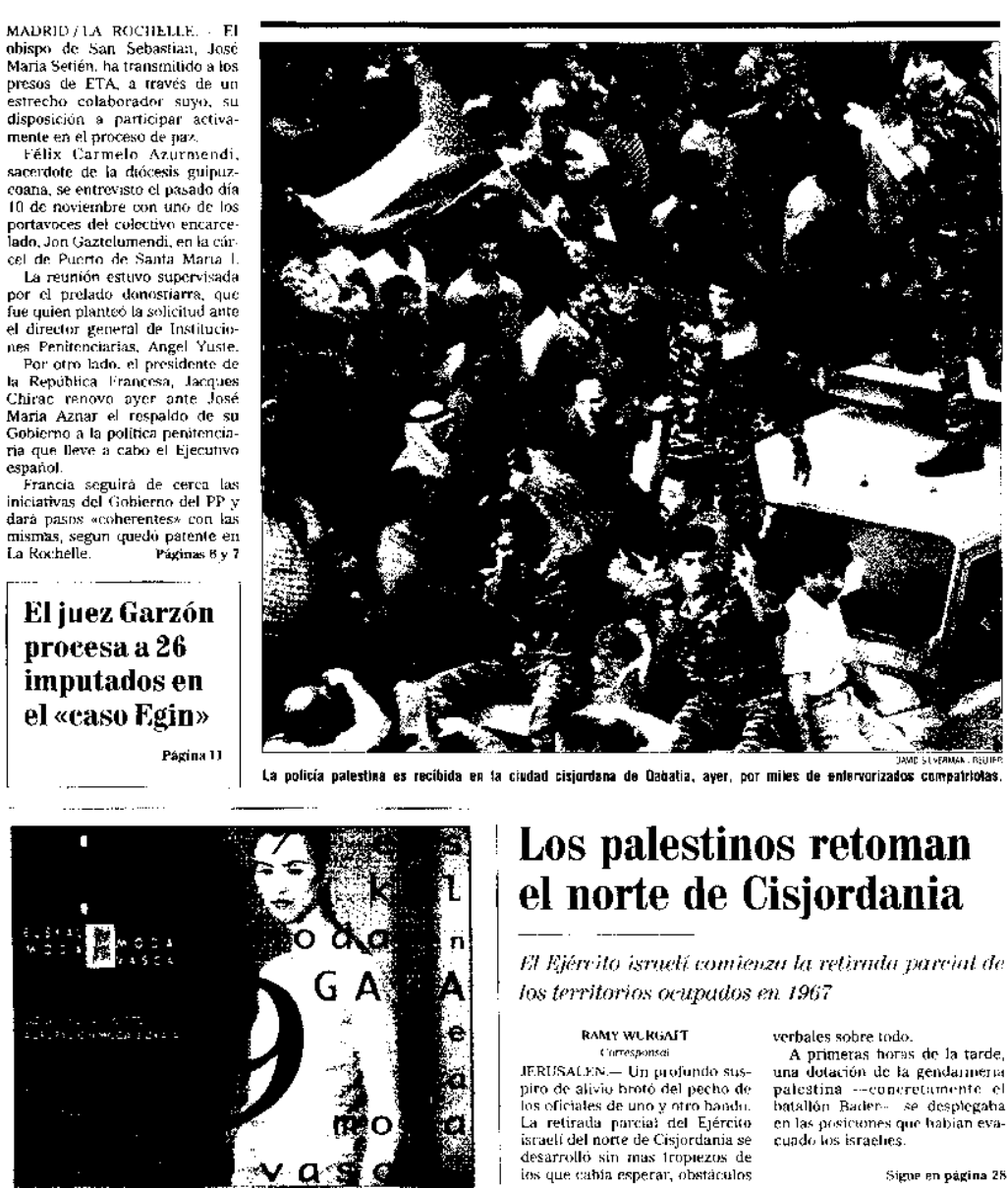

\section{Los palestinos retoman} el norte de Cisjordania

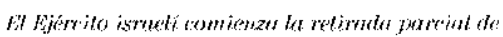
los torritorios orupados th 1967
FAMTY WL KLiNT

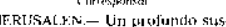

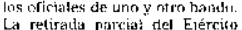

La retiratio prircià del Ejército
iscauti del norte de cisjordanja se

des arroollo sin inas 1roptercos de

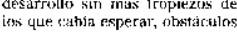

Jiro de alivit hrotó del pectho di:
A primerast thirls din la tarde

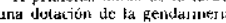

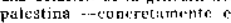
hatallor Radier.. be desphegat en las prisictemats qur labian ewachind do has is rastilies.

Signe en pakins at uerbales sobre todo.
Los barones lograu *in extremism que Almunia acepte el liderazgo de Borrell

- Fl candidato se converrira tias cl acuerdo en el principal portavoz e inter. locutor del HSOE

- I a Oficina que aproyala su cartidiatura desaparece. estructura slel partido.

- Queda pendiente su reclankficon de incremnenLar la puesencia de sus parlidlating en th diveoción rige 16,17 $\mathbf{s}$

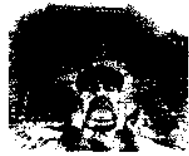

LA ESFERA

Cela vietve a la Mexurta 50 año después

\section{motol 2 VIAES}

I sts des cortas de Harloy Davklson

\section{LA REVISTa}

Varija Oswald: aE] acssingato dt Kennedy fue un golpe de Estado

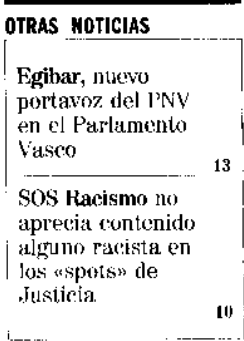


En la página 6 El Mundo amplía la información anticipada en la portada del periódico en un texto que titula Setién se ofrece a los presos de ETA para participar en el proceso de paz. Lo que para El Mundo en el titular de portada era el ofrecimiento de Setién para "ayudar" a la paz, se convierte en un ofrecimiento para "participar" en el proceso de paz. Una participación, además, que en el texto se recoge con la expresión "participar activamente" en el proceso de paz.

Como sinónimos de ayudar podríamos utilizar apoyar, favorecer, secundar, pero no participar, y mucho menos participar activamente. O El Mundo desconoce los términos exactos del ofrecimiento de Setién a los presos de ETA, o utiliza interesadamente la conversación mantenida por el emisario de Setién con Jon Gaztelumendi para expresar un hipotético ofrecimiento de la Iglesia vasca para mediar en el proceso de paz.

Al tiempo que da cuenta del ofrecimiento de Setién, el periódico aprovecha una entrevista concedida por Aznar al diario francés Le Figaro para exponer en un primer plano la postura del Gobierno de Madrid frente a las intermediaciones. Así, en una información titulada El Gobierno no quiere que haya intermediarios, explica que tanto Aznar como diversos portavoces del Gobierno han reiterado en las últimas fechas que el Gobierno rechaza tajantemente la posible intervención de mediadores.

En esa información recoge la siguiente frase del presidente del Gobierno de Madrid: En el País Vasco no habrá ni intermediarios ni mediadores, señala Aznar quien, tras asegurar que existen candidatos e incluso una internacional de la mediación, añade que muchos de sus miembros están en paro y que en España no encontrarán trabajo. 
- Un representante del obispo se entrevistó el día 10 con el recluso Jon Gaztelumendi en Puerto de Santa María - EA ha solicitado visitar al etarra Zabarte Arregi en Salto del Negro

\section{Setién se ofrece a los presos de ETA para participar en el proceso de paz}

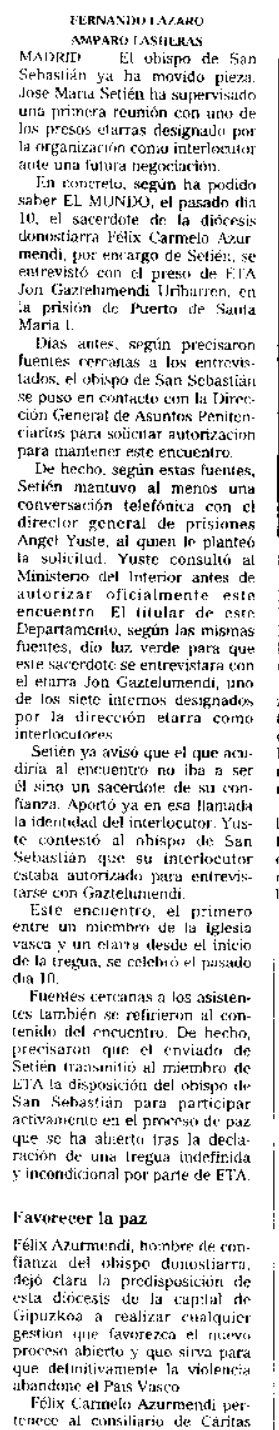

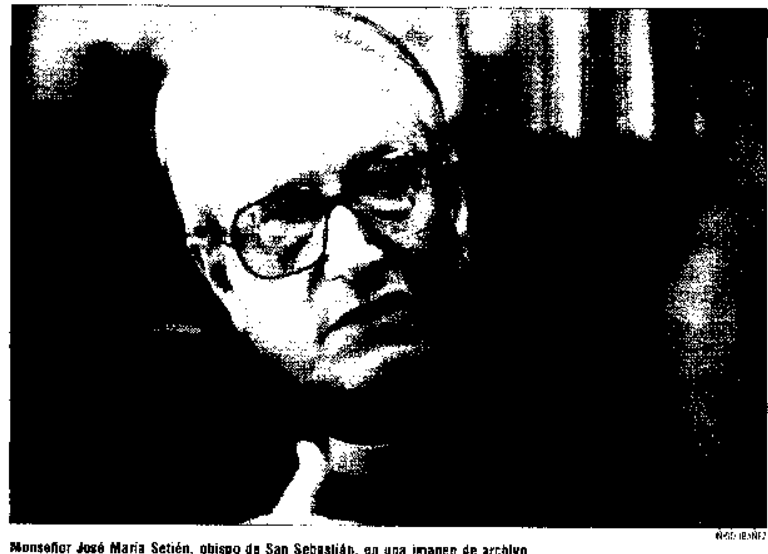

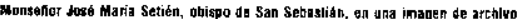

Dioesana de Sall Sebtitian. Desarrolla trabajo pissoral bajo nombre det que es de maxten. Confianza.

E.l etarrat $y$ ol waterchore andjzaron tambien la sifuaciór polt

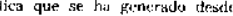
yue el pasado 1's dor sushember

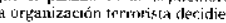
ra poner fin, al menus temperalinerste. a sus accioness violentian.

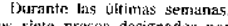

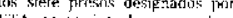

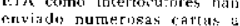

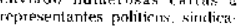
los y sucjutes del t"nis vas co

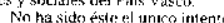

A) Giztetumendi, al preso que el pasado dia 10 so

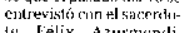
te Felix arasendi. ewvíldo por secien. pas durisio que pil trearlece entre rejas

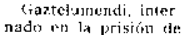
máxima segulduad Tue 4as 1. detel puetro de simlit

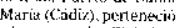

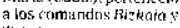

Tik inxestinctor del mpromentatle de bet:en

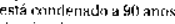
de car'cel pur numerosos
asesifliterti. Isenishatch

Fit) un equintros que arte press manlus dipulakin en ol congress do Ixquierda L'sida Withy Mayer. ie transmits is: sit.

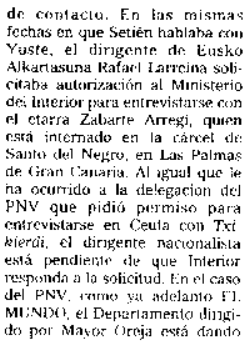

latgas antes
بnguentro. Esle preso de FTA envio ura

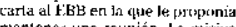
thathenter una reluminn. La misiva inviraciot prestisamente unt

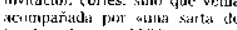

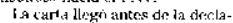
ratcicin de iregua y al libar solicito ei permiso para celebray el encutentro. Según el JPNy el Antiteratio dro Estade pireid la Septiarifad, kjeardo Marti hluxa

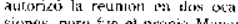

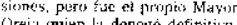

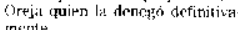

\section{Gaztelumendi, uno de los defensores de la «nueva fase»}

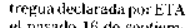

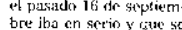
ha thicho ba wha num

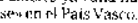

de bis seis presos do mados por la direccion do

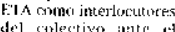

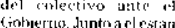
rohetrlib duntharlestan lend. Trikteldie Jesas Maria Kathatro Atregi. jerra Kétäte. Mejcedte

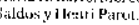

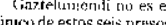

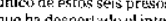
tess de los pratiden politi

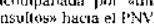

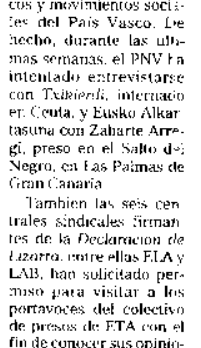

Des: y lit posisisin que milastie ther sobturc el pro

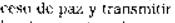
Irs kax projlox de vista schere esta turticis que misnlie

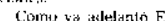
ML:NDO a Ginhiem

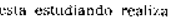
un muevit gesith plutrifen ciarion antres de las focstid. de Navidad. lintret las hiputesio ane trarala af Grobiernos. Jin mos probasile es lat de Hist Pensisula de los 21 rectly.

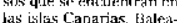

El Gobiermo no quiere que lava intermediarios refroro mer bo ujd minetis

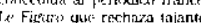
on

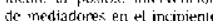
cliakingu con la band amal

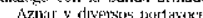

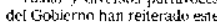

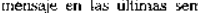
nak, asegrurando que el bjecutiwn quiere conoter direat mate las inlenciones de FT/ ryentarmente al inichis de tuat quire megociatzon o clálogo alin el Iais vasuro no habr mii intermedianios sí mediad mo, mital a herar quien. tra ascouras que exister: Landid. $10 \mathrm{~s}$ - $\rightarrow$ inteluses una internteti

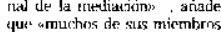

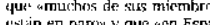

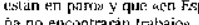

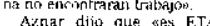
quisn tictic que aportar quitin ticth que apkistar lis

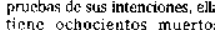
sabre su conciencis EJ presidente diju yoe no

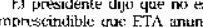

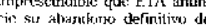
la volencia en un comunisad pultsico. *Plocederemón con

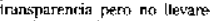
now las negoriacionds cont errisilumes con dirnelo, Jas espanoles sabran ruartho tel Gobserno whitime: que las comdicinte

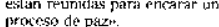
Fio

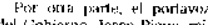

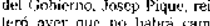

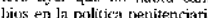
mientrats an ac acrodito ta

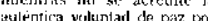
pure de FThw y reizali que

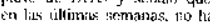

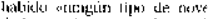

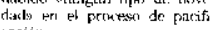
caciom.

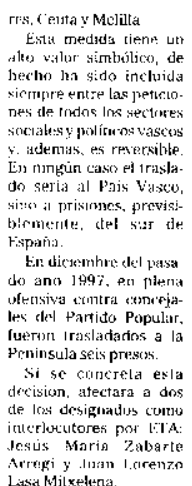


Al colocar en esa misma página el ofrecimiento de Setién para participar en el proceso de paz con la negativa del Gobierno a que haya intermediarios, $E l$ Mundo identifica el ofrecimiento de José María Setién con la intermediación. Así, acaba por presentarse en un mismo plano los términos ayuda, participación, participación activa, intermediación, lo que no hace más que añadir confusión y desvirtúa los términos exactos del contenido de una conversación que El Mundo, además, parece desconocer.

Se podría argumentar, cosa que no es así, que se trata de matices carentes de importancia. Si así se piensa, convendría recordar el editorial del sábado 7 de noviembre en el que El Mundo reivindicaba la importancia de los matices y argumentaba que va ser necesario acostumbrarse a los matices porque suelen ser claves en las negociaciones por la paz. También son importantes, decimos nosotros, en la información de los medios de comunicación en los temas relacionados con la paz.

La interpretación interesada que el periódico hace del ofrecimiento de Setién, vinculándolo a una solicitud de intermediación, queda clara en el pequeño editorial (glosa) que El Mundo publica ese mismo 21 de noviembre titulado La Iglesia ofrece sus buenos servicios para la paz vasca en el que explica la posición de Aznar frente a las intermediaciones y analiza en ese contexto la entrevista del enviado de Setién con Jon Gaztelumendi.

Después de vincular la conversación del representante de Setién con un ofrecimiento a la mediación, el editorialista rechaza cualquier posible mediación futura de la Iglesia vasca y expone claramente: No se trata de que la Iglesia católica intermedie en nada. Pero no sobra que esté informada, por si en un momento dado pudiera ayudar de un modo u otro a la consecución de la paz.

Con este nuevo punto de vista sobre el papel de la Iglesia vasca en la búsqueda de la paz, El Mundo, además, matiza los argumentos que utilizaba en su editorial del 19 de setiembre para defender vehementemente la importancia del papel intermediador que podía o incluso debía jugar la Iglesia vasca. Exactamente dos meses después, tras los reiterados pronunciamientos del Gobierno en contra de cualquier mediación, El Mundo acepta que la Iglesia vasca esté bien informada, pero pasa a negar el posible papel de mediación que inicialmente opinaba que podía y debía de jugar.

Al vincular el ofrecimiento de José María Setién a Jon Gaztelumendi para ayudar en el proceso de pacificación como un intento de mediación de la Iglesia en el conflicto vasco, El Mundo provoca que al día siguiente el ministro del Interior español, Jaime Mayor Oreja, rechace cualquier mediación de los obispos vascos. Así, el 22 de noviembre El Mundo titula en su página 8: Mayor Oreja pide al obispo Setién que rece, pero rechaza su mediación.

En ninguno de los textos publicados los días 21 y 22 de noviembre, $E l$ Mundo justifica que se haya producido un ofrecimiento de mediación por parte de 
la Iglesia vasca. Sin embargo, a pesar de ello, ese periódico sigue manteniendo esa tesis.

El 22 de noviembre, en el texto que publica El Mundo en su página 8 en el que explica el rechazo de Mayor Oreja al ofrecimiento de mediación de la Iglesia vasca, El Mundo informa en su primer párrafo de lo siguiente: El Gobierno español expresó ayer, a través del ministro del Interior, Jaime Mayor Oreja, su rechazo a la mediación ofrecida por el obispo de San Sebastián, José María Setién, en el proceso de paz.

Este periódico sigue insistiendo en el ofrecimiento de mediación, a pesar de que en esa misma información publica el desmentido de un portavoz de la Iglesia vasca. Así, unos párrafos más abajo El Mundo publica las siguientes declaraciones de un portavoz autorizado del Obispado de San Sebastián: Desde hace 30 años es públicamente conocida la voluntad de Setién de hacer todo lo posible por alcanzar la paz. Otra cosa es que el obispo se haya ofrecido a mediar en la cuestión de los presos, lo que es absolutamente incierto.

El 27 de noviembre El Mundo recoge en su portada algunos puntos de la Pastoral de Adviento de José María Setién, dedicada casi exclusivamente al proceso de pacificación. Como puntos más significativos de la Pastoral ese periódico destaca los siguientes:

1. Sugiere que el proceso de paz puede exigir que se cuestione el marco jurídico.

2. Antepone los derechos de las víctimas y el acercamiento de presos a la negociación.

3. Propone que la sociedad vasca estudie, debata y valore el ejercicio del derecho de autodeterminación.

4. Advierte a los partidos vascos de los riesgos del bifrentismo defensivo o agresivo.

En un editorial publicado por El Mundo en su página 3 explica sus coincidencias y discrepancias con los argumentos del obispo vasco. Así, El Mundo afirma que coincide con su apelación a los partidos a superar el bifrentismo y también en el acercamiento de los presos a cárceles cercanas al País Vasco. El punto de discrepancia lo sitúa en la defensa del derecho de autodeterminación.

En ese mismo editorial El Mundo rechaza la posibilidad de que la Iglesia vasca juegue el papel de mediadora en el proceso de pacificación. Así, afirma que los obispos vascos no necesitan asumir una hipotética mediación para desempeñar un papel relevante en las negociaciones que se avecinan.

El 29 de noviembre los medios de comunicación recogen una declaración pública firmada por más de 200 familiares de víctimas de ETA y alguna víctima del GAL en la que, entre otras muchas más cosas, reclaman que los autores de los atentados deben expresar arrepentimiento, afirman que la Comisión de Derechos Humanos del parlamento Vasco nunca se ha interesado por su situación 
y denuncian la indiferencia de la Iglesia vasca durante todos estos años de conflicto.

El texto aparece publicado por El Mundo en su página 9 bajo un titular en el que se lee: Las víctimas del terrorismo se sienten olvidadas por los políticos y la Iglesia. Un titular que se ajusta perfectamente a lo que manifiestan en su declaración pública los familiares de las víctimas.

Ese mismo día El Mundo abre su portada con esta información, aunque, con un titular sorprendente en el que se afirma: Estalla la polémica entre el obispo Setién y las víctimas del terrorismo. Los familiares de las víctimas de ETA no manifiestan en ningún instante su intención de polemizar con el obispo Setién por sus declaraciones, ni tan siquiera le citan en su declaración. Lo que hacen es criticar lo que ellos consideran abandono por parte de los partidos políticos y la Iglesia.

Es más, las declaraciones de los familiares de las víctimas de ETA constituyen, sin más, una crítica o censura, pero en ningún caso se establece una polémica entre Setién y los familiares de las víctimas de ETA.

El Diccionario de Uso del Español de María Moliner explica en los términos siguientes la palabra polémica: Controversia, discusión, disputa. Diálogo, particularmente por escrito, por ejemplo mediante artículos publicados en los periódicos, en que cada uno de los participantes sostiene cierta afirmación y ataca la del contrario.

Ciertamente, los familiares de las victimas de ETA critican el papel de la Iglesia vasca, pero sin atacar para nada a Setién. Además, Setién no menciona para nada, y mucho menos a modo de crítica, a los familiares de las víctimas de ETA, por lo que la polémica no existe por ninguna parte.

A pesar de ello, El Mundo no duda en dotar a su información de unas claras connotaciones sensacionalistas y desvirtúa la realidad presentando una crítica genérica al papel de la Iglesia realizada por los familiares de las víctimas de ETA como si se tratara de una polémica entre el obispo de Donostia y esa asociación.

El 14 de diciembre de 1998 se produce un vuelco importante en las informaciones sobre el obispo de San Sebastián José María Setién. Ese día, El Mundo utiliza una carta privada entre el obispo vasco y el dirigente de ETA Jon Gaztelumendi para destruir cualquier posibilidad mediadora de la Iglesia vasca. 


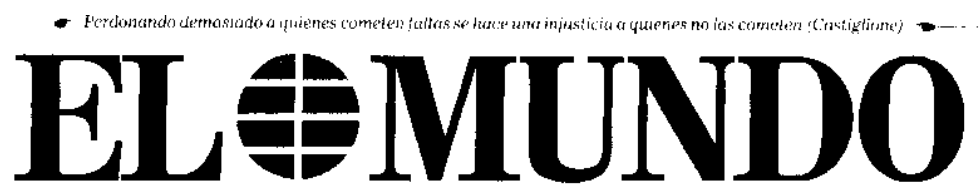

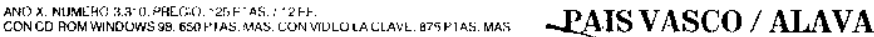

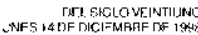

VETERINARIA/ inon perros reciben tratanuento "psiquiátricon con fármucos en España/33

\section{Setién escribe a un etarra condenado por 9 asesinatos y lo llama «preso político»}

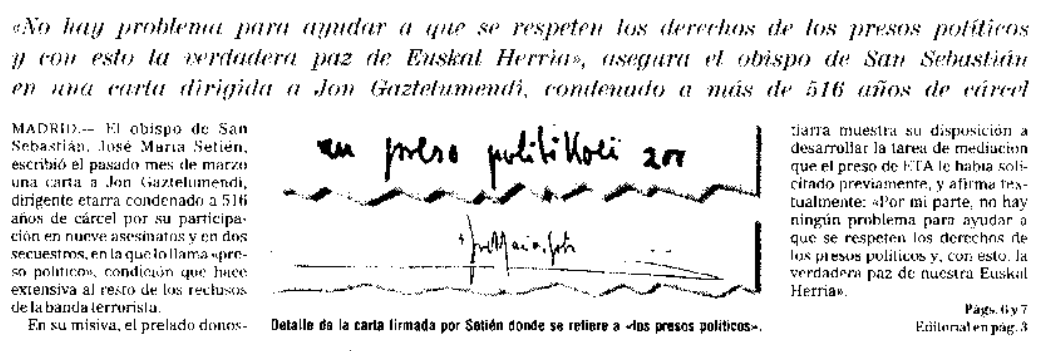

Orden de prisión para dos de los tres detenidos por el asesinato de Aitor Zabaleta

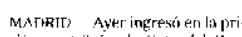
sicin madrikena de Sorts deth Retal

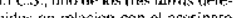
lon

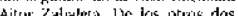

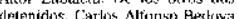

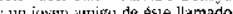

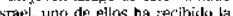

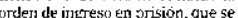
cumplicá en lis próximas horas. y al magurdo hal sidon puesto a distinicion del juzgalo de tertano

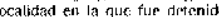
Ayer, los jugudores de la Rerit

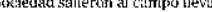

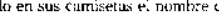
abratetat Er. cast lodos los carspos

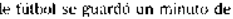
silencin.

Piplnal 14
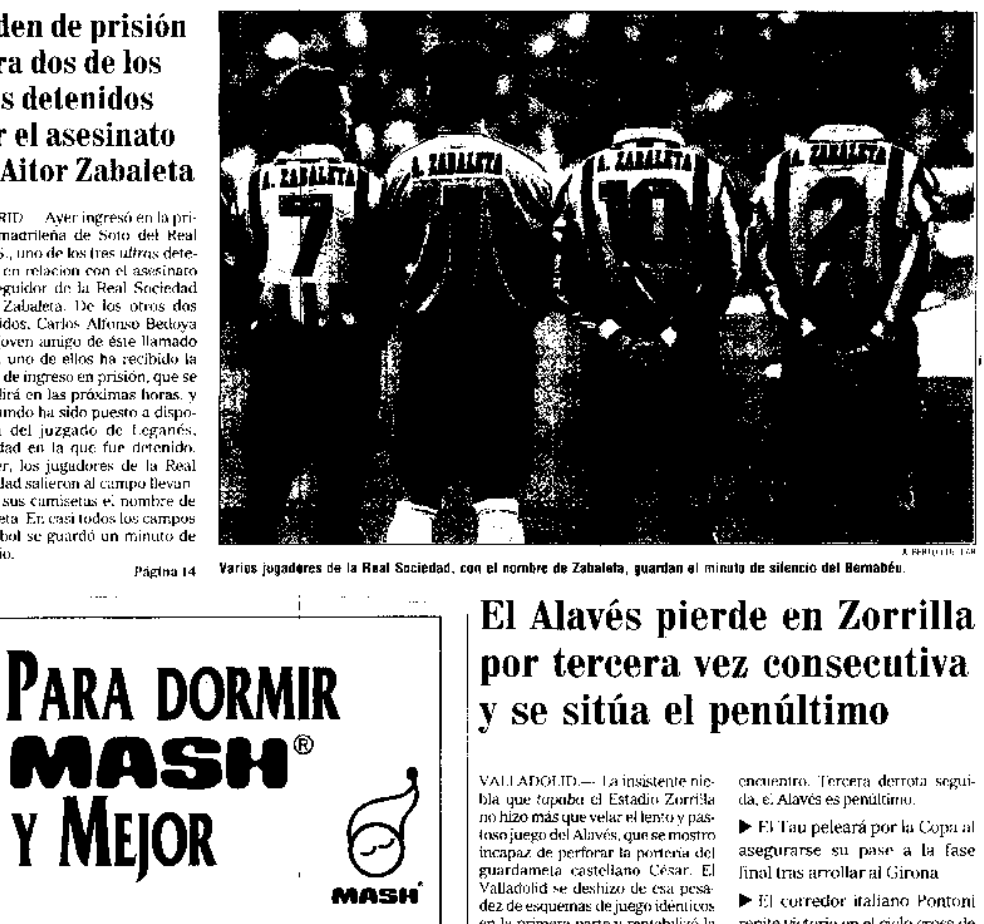

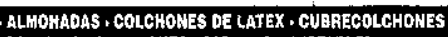
I SOHAERES - EDAEDOWES , SABAHAS AJUSTAELES
El Alavés pierde en Zorrilla por tercera vez consecutiva y se sitúa el penúltimo

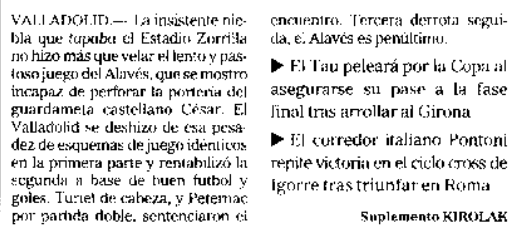

Fl Ayuntamiento de Madrid meadificó un terreno fi dias despues de cune lo comprara el gnpho de Loremzi Surz

- Fl presidente dat keta Madrid y rus socicis: insuobiliariós ganan cم la opetación juás do 2 inh millones de prestelas yas qute paso a waler tand semana

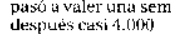
Priginal 12

OTRAS NOTICIAS

El PP wasco denuneriat que la tiumpariaz do: hostigamento protende critar que frome listats elextortales

\section{Lina juez}

domostiatary, acessidada pour el] presidented de sul Salade dejarse influir pore el poder politiso

El presidente de lilit: no corymers at Nelanyathu para yopetes Acuerdo ide wye

El director do la Asciniakiont ontra al cánes:

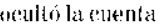
rle lat IFE.

VIVIRAQUI.

LaOXG vasca

Hîlugarten

Gunduat:

Bakea. I're!mio

Fidrojeo de la

Solddaridad 
El Mundo, como es lógico, oculta la procedencia de la filtración de la misiva y cita como fuente de información a: "una carta a la que ha tenido acceso $E l$ Mundo". De los aspectos tratados en la carta dirigida por Setién a Jon Gaztelumendi, el periódico censura fundamentalmente uno: que el obispo de Donostia califique a los miembros de ETA como presos políticos.

En un editorial publicado ese mismo día titulado Setién ha ido esta vez demasiado lejos, el editorialista de ese periódico afirma que es inaceptable que el obispo considere a los etarras -y en concreto a los que han cometido delitos de sangre-presos políticos.

A partir de ahí El Mundo considera que Setién demuestra una visión demasiado parcial y sectaria del proceso vasco, por lo que, según concluye ese diario, ha dado un paso en falso que le excluye de cualquier futura mediación y alienta la desconfianza hacia su actitud y la de parte de la Iglesia vasca.

El 15 de diciembre El Mundo abre su portada con unas declaraciones del presidente del Gobierno español: Aznar responde a Setién: No se entera del país en el que vive. 


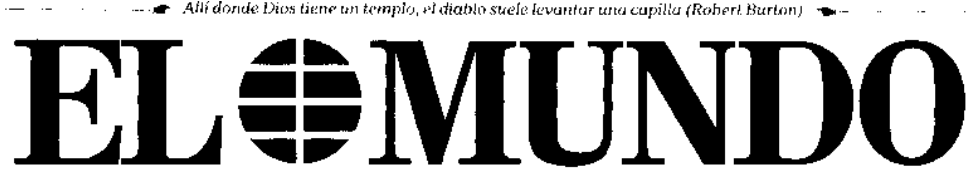

Woody Allen a ĞL MUNDO-uta persecución de Clinton es una desgracia nacional»/51

\section{Aznar responde a Setién: «No se entera del país en el que vive»}

- Tacha de aestrafaleuias sus manifestaciones en la carta a Gaztelumendi - Las victimas rle ETA y de los GAL denuncian ula escandalosa comprensión de la iglesia vasca por los asesinos"

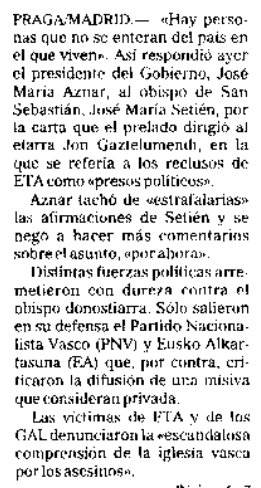

Detenidos

otros dos

«ultras» por el

asesinato de

Aitor Zahaleta

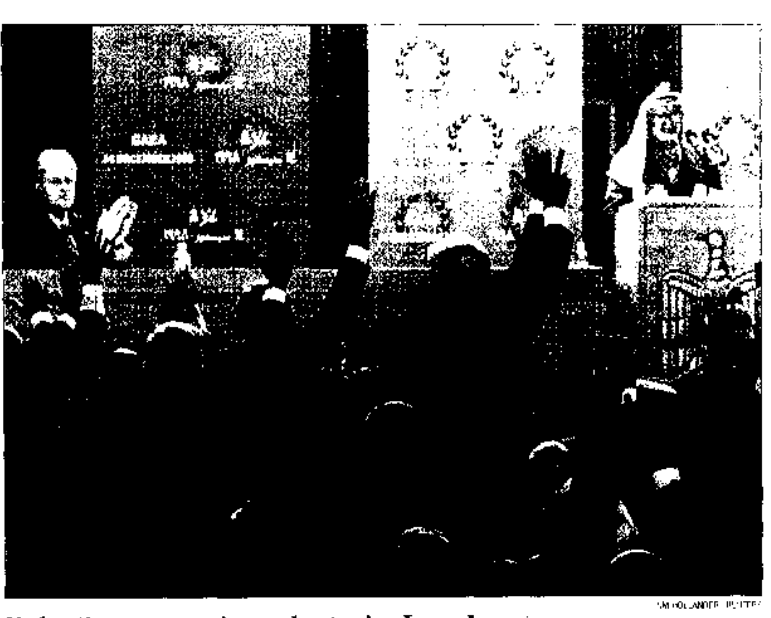

Palestina renuncia a «destruir» Israel

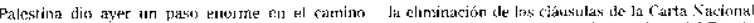

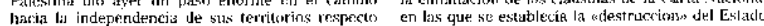

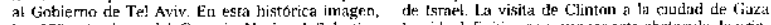

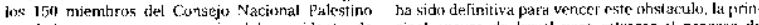

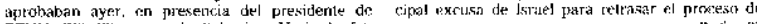
Páplital
La burocracia del Ayurtaniento puso en evidencia e] fovoritisimo hacia el grupo de Lorenzo Siny.

- Inos meses despues de

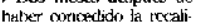

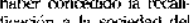
ligukin a lit somiedad del

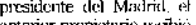
anterser propeteturio restoin

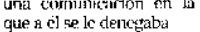
- tu psitir dice que wen osla operación. se ha dadu aulentiza prevarica-

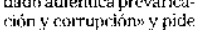
cimon yourupion" y pide al jiscial que irjerve - IU seriala que inlginaros concejalos parasen mis delegados de Sarz qu represontantes pubucos:

OTRAS NOTKCIAS

EIPNY milcra

en cl Senado su

possturt.

contrarial a los?

Prosijpucstas

del Fratada

Ja LE bari una andiluria al pjogpezma do laz lusthatemint (4) chintere

Julio Sulinas

voclue paric

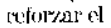
alingue dot Alaves

S'úńtez manticmo? a. Virn Gial pese a la opjoiom on contra de

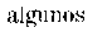
jugeterores

VIVIRAQUI

Fi Gusgenheim atriplía cen 1.21 ir millones sil

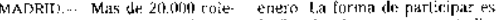

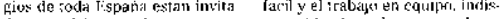

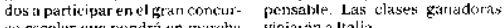

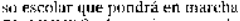
prosupuesion para 1993 
En un editorial pequeño (glosa) publicado ese día y titulado Algo falla en el mensaje evangélico de Setién, El Mundo se ratifica en sus puntos de vista del día anterior al afirmar que el polémico obispo ha ido esta vez demasiado lejos. Aunque, a continuación, niegue que como dice el peneuvista Anasagasti, quieran satanizar a monseñor.

Posiblemente El Mundo no tuviera la intención de satanizar a José María Setién. Posiblemente así fuera, aunque lo cierto es que la frase que encabeza diariamente el periódico y que sitúa por encima del nombre del diario indica todo lo contrario.

Diariamente $E l$ Mundo publica una frase en la parte superior de la portada del periódico que siempre tiene relación con el tema de apertura de ese día. La frase que encabeza la portada del 15 de diciembre de 1998 afirma lo siguiente: Allí donde Dios tiene un templo, el diablo suele levantar una capilla (Robert Burton).

Una frase que contradice la afirmación del periódico de que su intención no era la de satanizar a monseñor Setién.

El Mundo, que en su editorial del 19 de setiembre no dudaba en destacar la posibilidad futura de mediación de José María Setién y argumentaba a favor de ello, entre otros muchos aspectos, los excelentes contactos del obispo con miembros del llamado MLNV, aprovecha ahora una carta filtrada al periódico en la que califica de presos políticos a los miembros de ETA para excluir a la Iglesia vasca y a José María Setién de cualquier posible mediación.

Lógicamente, a partir del mismo instante en el que El Mundo publica la carta surgen las preguntas: ¿De dónde proviene la carta de José María Setién? ¿Quién la filtra? ¿Con qué intención? ¿Por qué El Mundo publica la misiva a pesar de que con ello conculca el derecho a la privacidad de monseñor Setién? ¿Por qué el cambio radical de El Mundo en su consideración de Setién como posible mediador?

Lo cierto es que El Mundo participó en la conculcación del derecho a la privacidad del obispo en sus comunicaciones privadas. Tal y como afirmó el ex lehendakari vasco José Antonio Ardanza dos días después de la publicación de la carta: Aquí nadie cuestiona que detrás de todo esto hay una violación flagrante por parte de un Gobierno que se dice de un Estado de Derecho en el que no se puede conculcar impunemente unos derechos.

Desde el 16 de setiembre de 1998, fecha de la declaración de tregua de ETA, hasta el 14 de diciembre de ese año, fecha en la que se publica la carta de monseñor Setién con Jon Gaztelumendi, El Mundo va evolucionando desde la consideración de Setién como inmejorable mediador hasta la afirmación de que el obispo vasco no puede jugar ese papel. 


\section{Cambio de posiciones}

1.-A lo largo de estos tres meses podemos observar en El Mundo tres fases bien definidas:

a.- Desde el 16 de setiembre hasta el 29 del mismo mes El Mundo apuesta por la mediación de la Iglesia en el conflicto vasco y, en particular, por el importante papel que puede jugar José María Setién. Los argumentos más importantes que utiliza son los siguientes:

- La iglesia ha llegado al momento presente en excelentes condiciones para desempeñar un importante papel de mediación.

- No sería la primera vez en la España de los últimos decenios que la Iglesia realizara labores de concordia política.

b.- Desde el 4 al 29 de noviembre El Mundo mantiene una posición crítica con la mediación, aunque no cierra totalmente las puertas a esa posibilidad. Es en esta etapa cuando aparecen las primeras declaraciones del Gobierno de Aznar en contra de cualquier mediación. A lo largo de ese mes El Mundo publica las siguientes afirmaciones:

- La paz es cosa de todos, de ahí que sean positivos los esfuerzos de la Iglesia, pero el Gobierno ha dejado claro que no quiere intermediadores.

- No se trata de que la Iglesia católica intermedie en nada.

- No necesitan los obispos asumir una hipotética mediación.

c.- A partir de diciembre se produce un giro importante en las informaciones de El Mundo. Desde esa fecha cierra las puertas a cualquier posibilidad de mediación de la Iglesia vasca, en general, y de Setién, en particular. Estos son los argumentos más importantes:

- Setién ha ido esta vez demasiado lejos.

- Es inaceptable que considere a los etarras presos políticos.

- Ha dado un paso en falso que le excluye de cualquier futura mediación.

2.-El Mundo rectifica las declaraciones del portavoz del Gobierno Josep Piqué, quien afirmó el 7 de noviembre que el Gobierno no pondría condiciones previas respecto a las interlocuciones.

Según El Mundo, las declaraciones de Piqué podían conducir al equívoco de que el Gobierno estaba dispuesto a dialogar con cualquier mediador nombrado por ETA. El Mundo no duda en desmentir al propio portavoz del Gobierno y afirma que el Ejecutivo popular no aceptará mediadores venidos de otros países que puedan contribuir a internacionalizar la negociación.

3.-El Mundo tergiversa el ofrecimiento de José María Setién para "ayudar" al proceso de paz y lo presenta como una disposición del obispo de San Sebastián para "participar activamente" en el proceso de paz.

Para publicar esta información El Mundo utiliza textualmente a la hora de citar a la fuente de información la expresión «según ha podido saber El Mundo», 
una expresión -coletilla- que busca enmascarar ante el público a la fuente de información que le ha aportado los datos.

4.-El 14 de diciembre de 1998 El Mundo publica una carta privada entre Setién y el miembro de ETA Jon Gaztelumendi. El Mundo utiliza la correspondencia privada del obispo para abortar cualquier posible intervención futura de Setién como posible mediador.

A través de una fuente de información que $E l$ Mundo no cita y oculta bajo la expresión «según una carta a la que ha tenido acceso El Mundo...» el periódico participa activamente en un intento por descalificar a monseñor Setién.

El Mundo no duda en publicar una misiva privada de Setién, rompiendo el derecho del obispo vasco a la privacidad y trasgrediendo una norma de carácter deontológico, para, con una finalidad claramente desinformadora, colaborar en la estrategia política del Gobierno o de algún aparato a su servicio para descalificar a Setién.

En esta ocasión, El Mundo utiliza una filtración y se pone al servicio del Gobierno para romper con un hipotético papel mediador del obispo vasco, rompiendo la coherencia del discurso mantenido por el medio de comunicación a lo largo de los últimos meses y contradiciendo los presupuestos que libremente defendió con anterioridad destacando la importancia que el obispo de San Sebastián podía jugar en la búsqueda de la paz.

\section{III.- Algunas conclusiones derivadas del estudio}

1.- Una estrategia importante de la política informativa de los medios de comunicación es la de aparentar una permanente fidelidad a los principios políticos e ideológicos recogidos en sus actas fundacionales. Por eso, cuando en un medio de comunicación se producen cambios estratégicos, casi nunca derivan de una radical transformación, sino de una casi imperceptible evolución gradual adoptada por el medio de comunicación para acomodarse a nuevos espacios sin que su audiencia note el brusco cambio que se está operando.

Al tiempo que ensalzan esa fidelidad a sus presupuestos básicos, también están interesados, al menos aparentemente, en dar sensación de coherencia en los discursos que proyectan a sus audiencias en situaciones informativamente complejas.

Sin embargo, la coherencia no es más que una estrategia periodística. Al final, más que la coherencia o incoherencia, le interesa conservar una audiencia y defender una política informativa afín con los grupos sociales, políticos o económicos que más le interesan en cada instante.

Si para conservar esas alianzas estratégicas debe modificar su discurso, lo hace, aunque para ello, de puertas hacia fuera, intente dar una imagen diferente. No le importa entrar en contradicción con sus presupuestos básicos si obtiene el reconocimiento de los grupos que le son afines. 
2.- En los primeros instantes posteriores a la declaración de tregua por parte de ETA, se produce un desfase entre los puntos de vista defendidos por $E l$ Mundo y los que defiende su grupo afín, el Gobierno del PP. Este desfase inicial le lleva a defender puntos de vista que entran en contradicción con los defendidos oficialmente por el Gobierno. Sin embargo, conforme van pasando las fechas y se van asentado los puntos políticos sobre los que el Gobierno va a desarrollar su estrategia, El Mundo desea compartir los criterios del PP y rectifica, siempre que así sea necesario, los presupuestos ideológicos mantenidos con anterioridad. Rectifica incluso en aquéllos puntos que en ocasiones anteriores y en circunstancias similares han merecido para el medio la consideración de principios.

3.- A pesar de las divergencias iniciales, derivadas fundamentalmente del desconcierto político creado tras la declaración de tregua indefinida por parte de ETA, El Mundo va orientando rápidamente su estrategia informativa hasta asumir plenamente las posiciones mantenidas por el Gobierno del PP y el Partido Socialista. Al tiempo, como es lógico, inicia una política agresiva hacia las iniciativas de los partidos nacionalistas vascos. A partir de ese instante, cualquier iniciativa de las organizaciones nacionalistas no es más que un pulso al Estado. La ayuda a la Asamblea Kurda es una bofetada a Aznar y la decisión supone suplantar las competencias atribuidas en exclusiva al Ejecutivo central, son los argumentos que más utilizará El Mundo para oponerse a la ayuda a los kurdos.

4.- El Mundo desarrolla una clara tendencia a la personalización de las divergencias con la intención de evitar dar profundidad a sus argumentaciones y devaluar el alcance del debate que permanece en el fondo de las discrepancias. De esta forma, además de tratar una discrepancia de fondo como si se tratara de una simple divergencia entre partes, sustrae a la audiencia la posibilidad de ahondar con criterio propio en la profundidad de las cosas.

El Mundo evita analizar con rigor los aspectos positivos y negativos que puede tener la intermediación en una situación de conflicto como la existente en el País Vasco. De esta forma, no proyecta sobre su audiencia argumentos consistentes sobre el papel genérico de la mediación. El Mundo prefiere personalizar el problema en la figura de monseñor Setién para descalificarle a él y a la Iglesia vasca como posibles intermediadores y, de paso, echar por tierra la posibilidad de cualquier otra intermediación.

5.- Al presentar como una discrepancia coyuntural lo que es una divergencia de fondo, El Mundo evita una exposición global de los orígenes del conflicto, sus motivaciones políticas, culturales, idiomáticas, étnicas, etc. Se trata de desvincularlo de su contexto, presentarlo como si de una reivindicación injusta se tratara. 
¿Qué quieren los vascos si tienen un estatuto con competencias inigualables en los países europeos?

Esta desvinculación de los problemas de su contexto genérico, deriva en una presentación del conflicto como si se tratara de una sucesión de pequeños hechos aislados. Al exponer así los temas, se presentan fuera de su contexto y de las causas que pueden originarlos. De esta forma, los hechos se producen sin que existan causas aparentes que los provoquen, aislados, sin vinculaciones.

La percepción se convierte así en un contacto superficial con unos hechos que parecen concatenarse de forma casi casual y el lector pierde la perspectiva de los conflictos y las causas que están detrás de ellos. Los hechos nuevos que van sucediendo se superponen a los pasados en una bien pensada concatenación, movida por una cierta sensación de suspense creada por los giros nuevos que adopta una información que no acaba por profundizar en la esencia de los temas. El lector observa la existencia de árboles en un primer plano, pero no acaba por ser capaz de percibir que éstos ocultan un bosque.

$\mathrm{Al}$ no existir una información en profundidad el lector se tiene que conformar con tópicos puestos a su alcance por los medios de comunicación, argumentos parciales o escasamente profundos. De esta forma el público carece de oportunidad para la reflexión profunda sobre los temas y desaparece el espíritu crítico de un público que se encuentra desprotegido ante los media.

Dentro de este marco informativo, en los textos interpretados por el periodista, en las crónicas que incluyen comentarios periodísticos, en las columnas o los editoriales, en general en todos los géneros interpretativos o argumentativos, el periodista aporta sus puntos de vista no con la intención de ayudar al público a profundizar en los temas, sino para que excluya las versiones que son diferentes a las propuestas que le hace. Es decir, para homogenizar su discurso.

Los media profundizan así en la pasividad del público y van construyendo la ideología sobre la que quieren asentar el pensamiento de la gente.

6.- $\mathrm{Al}$ presentar de forma unilateral los conflictos, al excluir una y otra vez los argumentos opositores, al fortalecer de forma compulsiva los argumentos del poder, los medios afines sustituyen su papel informador por un papel eminentemente propagandístico. Solamente informan de lo que interesa al poder y así la propaganda de los puntos de vista institucionales impregnan las páginas de los media.

Además, se muestran especialmente preocupados por presentarse ante el público como medios informativos, estrictamente neutrales, profesionales. Los medios propagandísticos son los del campo contrario, los que hacen hincapié en las versiones de la oposición. 
7.- Los medios de comunicación no son unos meros narradores de las situaciones de conflicto. Intervienen directamente para sacar el mayor provecho posible. Se alían con una de las partes, siembran la discordia o distraen la atención hacia aspectos que son de su interés. Desde esta perspectiva, tal y como afirma Héctor Borrat $(1989,31)$ el periódico no es sólo "narrador", sino también "comentarista"; y puesto en situaciones de conflicto, a veces puede tener una involucración mucho más intensa que la de la tercera parte: puede ser "parte principal" en el conflicto. De ahí que este autor considere al periódico como "narrador, comentarista y participante del conflicto político".

El medio de comunicación es parte del conflicto porque, en ocasiones, incluso dirige la información de los políticos afines a sus tesis. Puede presentar de la forma más favorable posible los puntos de vista con los que converge. Incluso puede, en ocasiones, dirigir directamente la información y «da instrucciones» a los políticos sobre las estrategias más adecuadas. Puede participar de lleno y además intencionadamente en estrategias desinformadoras con la intención de manipular a la opinión pública.

Por eso, en informaciones especialmente conflictivas o en aquellas otras en las que parece percibirse una intención desinformadora es importante formularse cinco cuestiones fundamentales explicadas por Michel Collon: ¿quién origina la información?, ¿qué interés tiene en este asunto?, ¿qué ideología influye en el que habla?, ¿nos comunica correctamente el punto de vista contrario, y si no lo hace, dónde podemos encontrarlo?, ¿nos indica cuáles son las causas profundas del problema?

8.- El auténtico objetivo del Gobierno, sus aliados y, por extensión de sus medios de comunicación afines es el de resolver el conflicto sin coste político. El objetivo fundamental es el de desnudar el proceso de pacificación de reivindicaciones políticas.

Para ello, abre un frente que busca ansiosamente la unidad antinacionalista para frenar posibles marcos reivindicativos.

Precisamente por eso, para los medios de comunicación afines a las tesis del Gobierno, PNV y EA, desde su alianza con EH, han ido perdiendo paulatinamente sus componentes democráticos y han pasado a convertirse en cómplices de los «terroristas»

Los objetivos de esta política son múltiples: dejar la iniciativa en manos del bloque Gobierno del PP-PSOE; debilitar al bloque EH-PNV-EA; evitar las reivindicaciones nacionalistas; fortalecer las tesis centralistas. Cuanto más se retrase el proceso más previsibles son las fisuras en el bloque nacionalista. El PNV fue el centro de críticas de la campaña electoral vasca y también durante las generales de marzo de 2.000. El objetivo no es otro que el de intentar debilitar la cadena nacionalista por el eslabón previsiblemente más débil: el PNV-EA. 
9.-El medio simultanea con facilidad declaraciones oficiales con confidencias oficiosas. Siempre con una clara intencionalidad y siempre en la misma dirección. El caso Setién es paradigmático de esta política informativa.

Así, el medio de comunicación puede convertirse en parte activa de una manipulación y prestarse a filtrar informaciones sospechosamente interesadas. En ocasiones puede también no colaborar, pero en esos casos lo habitual es que guarde silencio por temor a las represalias que puedan provenir de la institución o grupo que está difundiendo las desinformaciones. Sólo cuando el medio se enfrenta a los intentos de manipulación y los denuncia públicamente podemos hablar de medios de comunicación independientes.

10.-Toda esta política informativa precisa de grandes medios y el poder los tiene. Algunos propios. Otros porque se prestan a trabajar para sus intereses. Otros -gabinetes de prensa, propaganda, publicidad, agencias de información etc.- porque canalizan los flujos informativos que el Estado desea.

11.-El periodista de hoy no necesita buscar las noticias que va a publicar. Las informaciones le llegan sin problema, incluso más de las que diariamente puede publicar. El periodista no selecciona a sus fuentes, son las fuentes las que buscan, encuentran y acaban por imponerse al mismo periodista.

12.-Las fuentes institucionales tienen cada vez más importancia en el trabajo periodístico:

Son unas fuentes baratas, suministran la información completa y lo hacen a través de sus propios equipos de trabajo y producción de noticias.

Además, al tratarse de fuentes institucionales se amparan en el prestigio de sus cargos para hacer innecesaria la verificación de las informaciones que suministran.

Las fuentes institucionales han ganado la batalla de la comunicación. Partidos políticos mayoritarios e instituciones públicas marcan los ritmos de la comunicación a través de empresas en las que influyen directamente (propiedad de personas relacionadas con determinado poder político) o indiretamente (a través de líneas de crédito, decisiones que benefician a las empresas, publicidad institucional, etc.).

13.-En un panorama como este el periodista se encuentra con las manos atadas. No puede oponerse a la marcha de su empresa sino quiere encontrarse marginado o en la calle. No puede oponerse al trabajo rutinario de comunicados que acuden a su mesa porque la productividad le obliga a someterse a los ritmos sencillos del trabajo periodístico.

Además, las fuentes institucionales premian y castigan a medios y periodistas. Pueden mantener una política de silenciar informaciones a determinados 
medios, o actuar en beneficio de otros. Pueden también sobreinformar a los medios para que no tengan la necesidad de buscar en otros sitios lo que el poder de forma sesgada les suministra.

Son tantas las ventajas de los medios que operan alrededor del poder o de los partidos que tienen posibilidades de alternarse en el poder que los medios han renunciado a la discrepancia.

Los medios así se orientan en una u otra dirección, pero con una idea de fondo común. Cuando se presentan discrepancias importantes los partidos se apoyan en el consenso y los medios también.

El poder acaba por silenciar la discrepancia y los medios acaban por situarse alrededor de los grandes grupos políticos o de opinión.

14.-Dentro de este marco de información institucionalizada, los medios pueden aprovecharse de las fugas de información, o del periodismo de investigación. Sin embargo, a pesar de ello, tanto las fugas como las investigaciones se realizan siempre desde los medios que apoyan a partidos en la oposición hacia los partidos del poder. Así, se garantizan la alternancia. Alternancia en el ejercicio del poder político por parte de los partidos y alternancia por parte de los medios en compartir los beneficios que reporta trabajar para el poder.

15.-Dentro también de este marco informativo, el poder, a través de los medios a su servicio, sabe que lo que no se va a publicar es como si no hubiera sucedido. A pesar de que existan pequeños cauces informativos para canalizar puntos de vista discrepantes, el poder sabe que la versión institucional acabará siendo la dominante entre la población.

En las situaciones de conflicto los medios cierran filas y se unen en la defensa de la versión oficial, que será la que finalmente quedará impresa en la memoria de la mayoría de las personas.

Para ello, aparecen las descalificaciones y se ponen en marcha los sistemas propios de la propaganda. Nada de profundizar en las cosas, nada de buscar las causas que mantienen los conflictos. Unas cuantas medidas descalificatorias alrededor de un mensaje que se construye no desde los argumentos, sino desde las descalificaciones. Nosotros somos los buenos y los demás son los malos. Nosotros lo hacemos todo bien y son los demás los que están equivocados tanto en sus tácticas como en sus estrategias.

Al final, aunque algunas versiones discrepantes lleguen a sectores de la población, la versión dominante será siempre la oficial, esa que se han preocupado tanto en machacar a través de auténticas campañas de prensa, a través de auténticas campañas de propaganda. 
16.-Toda esta política informativa está adornada de la exaltación de la «neutralidad» de algunos medios de comunicación. Los medios del poder no están vinculados a determinadas opciones políticas, ni tan siquiera al poder mismo. Se trata de empresas independientes que realizan un trabajo profesional, ajeno a cualquier ideología. El trabajo ideológico, escasamante profesional, lo realiza exclusivamente la prensa vinculada abiertamente a determinadas opciones políticas.

Los medios saben que es vital manejar estos registros. La aparente desideologización de los medios es un arma que utilizan para llegar con mayor facilidad a las grandes audiencias. De ahí su extremo interés en dar espacio a las voces medianamente discrepante en las páginas de sus periódicos, pero manteniendo una línea inflexible alrededor de los puntos políticos que defienden.

El público, de esta forma, se encuentra desprotegido ante unos medios preocupados en aparentar una cierta distancia política. El público, despistado, acaba por no darse cuenta de cuál es la ideología que está detrás del medio que compra.

El medio se ampara en la necesidad que tiene de dirigirse a públicos masivos, por consiguiente heterogéneos, para apelar a su supuesta independencia y profesionalidad neutra. La necesidad de abarcar grandes y amplios mercados publicitarios ha llevado a los medios a intentar ocultar sus vinculaciones ideológicas, para así acceder a sectores amplios que le garantizan la entrada en las grandes campañas y mayores beneficios.

La propia realidad política de un partido de poder de izquierdas, cada vez más de centro y una derecha, que busca también el centro, ha contribuido a difuminar los perfiles políticos de los partidos con opción a acceder al poder. Una tendencia a la ambiguedad que ha entrado también a los medios de comunicación, aunque de forma aparente, para llegar con más facilidad al público.

A través de esa ambiguedad la prensa se ha asociado definitivamente con los partidos de poder y se encarga de dar una visión unívoca dEl Mundo que nos rodea. La homogenidad informativa impregna en la actualidad a los medios de comunicación.

Si los partidos y por extensión los medios de comunicación alcanzan un consenso ante determinados temas políticos tienen garantizada la victoria sobre la discrepancia. Los actores del consenso podrán sacar adelante sus puntos políticos sin necesidad de acudir a métodos impositivos. La imposición siempre forma parte del bando contrario. Al final, cualquier versión discrepante será la culpable de la ruptura de pactos, acuerdos o ciertos consensos alcanzados con ella.

La idea es defender que todo es posible a través del sistema, pero se trata ésta de una premisa falsa. Cuando el sistema (Parlamento) decide algo contrario a las fuerzas consensuadas, basta con no aplicar las decisiones, no ponerlas en práctica. El Parlamento Vasco decidió el acercamiento de presos, pero el Gobierno 
de Madrid no quiso aplicar esa política. Esto sucede porque, de hecho, las grandes decisiones se adoptan fuera de esos centros democráticos.

17.-Inmersos en esta dinámica, la práctica totalidad de los periodistas cierran filas alrededor de las propuestas oficiales, institucionales. Aparece así en toda su extensión lo que Michel Colon denomina "periodismo patriótico" y explica sus características con una frase del periódico noruego Aftenposten que afirmaba: "La verdad se subordinará siempre a la victoria. En una guerra -en cualquier conflicto decimos nosotros- hay tareas más importantes que cubrir la información, y tienes que saber de qué lado estás".

\section{Y...... una reflexión:}

En una situación de conflicto tan polarizada como la del País Vasco, ¿qué papel deben jugar los medios de comunicación?, ¿pueden limitarse a describir el punto de vista de una de las partes?, ¿tienen la obligación de analizar la situación global y presentar los posibles móviles de cada uno?, ¿deben simplemente reproducir las versiones oficiales (gubernamentales) y alinearse claramente con ellas o deben también dar entrada a las otras versiones, mostrar las contradicciones, presentar los puntos de vista de expertos, etc...?, ¿deben profundizar en las bases del conflicto, en sus raíces, en las reivindicaciones, para ahondar así en la búsqueda de soluciones?. 